\title{
Application of a Novel Long-Reach Manipulator Concept to Asteroid Redirect Missions
}

\author{
John T. Dorsey, NASA Langley Research Center \\ William R. Doggett, NASA Langley Research Center \\ Thomas C. Jones, NASA Langley Research Center \\ Bruce D. King, NASA Langley Research Center
}

\begin{abstract}
A high priority mission currently being formulated by NASA is to capture all or part of an asteroid and return it to cis-lunar space for examination by an astronaut crew. Two major mission architectures are currently being considered: in the first (Mission Concept A), a spacecraft would rendezvous and capture an entire free flying asteroid (up to 14 meters in diameter), and in the second (Mission Concept B), a spacecraft would rendezvous with a large asteroid (which could include one of the Martian moons) and retrieve a boulder (up to 4 meters in diameter). A critical element of the mission is the system that will capture the asteroid or boulder material, enclose it and secure it for the return flight. This paper describes the design concepts, concept of operations, structural sizing and masses of capture systems that are based on a new and novel TendonActuated Lightweight In-Space MANipulator (TALISMAN) general-purpose robotic system. Features of the TALISMAN system are described and the status of its technology development is summarized. TALISMAN-based asteroid material retrieval system concepts and concepts-ofoperations are defined for each asteroid mission architecture. The TALISMAN-based capture systems are shown to dramatically increase operational versatility while reducing mission risk. Total masses of TALISMAN-based systems are presented, reinforcing the mission viability of using a manipulator-based approach for the asteroid redirect mission.
\end{abstract}

\section{Nomenclature}

$\begin{array}{ll}\text { ACS } & \text { Asteroid Capture System } \\ \text { ARM } & \text { Asteroid Redirect Mission } \\ \text { cg } & \text { center-of-gravity } \\ \text { ConOps } & \text { Concept of Operations } \\ \text { EB } & \text { Enclosure Bag } \\ \text { EVA } & \text { Extra-Vehicular Activity } \\ \text { GCD } & \text { Game Changing Division } \\ \text { HRS } & \text { Human Robotics Systems } \\ \text { MATLAB } & \text { MATrix LABoratory (software suite) } \\ \text { NEA } & \text { Near-Earth Asteroid } \\ \text { PMC } & \text { Polymeric Composite } \\ \text { RFI } & \text { Request for Information } \\ \text { SOA } & \text { State-of-the-Art } \\ \text { SRMS } & \text { Shuttle Remote Manipulator System } \\ \text { SSRMS } & \text { Space Station Remote Manipulator System } \\ \text { TALISMAN } & \text { Tendon-Actuated Lightweight In-Space MANipulator }\end{array}$




\section{Introduction}

A current high priority mission being formulated by NASA is to capture all or part of an asteroid and return it to cis-lunar space for examination by an astronaut crew. The initial mission concept involved rendezvousing with an entire small near-Earth asteroid (having a diameter of up to approximately 15 meters and a mass of up to 1,000 metric tons), capturing it, and redirecting it into a stable lunar orbit ${ }^{1}$. The two key elements of the mission spacecraft were a bus that used high-power solar electric propulsion and the asteroid capture system. The baseline capture system used a series of inflatable beams to deploy a fabric capture bag and then a series of cables (attached to winches at the spacecraft interface) to close the bag around the asteroid and reel it in against the spacecraft body. A more in depth feasibility study ${ }^{2}$ was conducted to examine key aspects of bringing the science, technology and human exploration communities together to accomplish the mission. The study also evaluated a number of potential asteroid targets and their characteristics (such as size, composition, mass and spin rates), compiled mission uncertainties and proposed and evaluated spacecraft and capture system concepts. The study concluded that it was technically feasible to find, capture and redirect an entire small, Near-Earth Asteroid (NEA) to the vicinity of the Earth-Moon system by the first half of the next decade.

Although retrieving an asteroid of the type specified in the initial study appeared feasible, there were many operational and asteroid characterization issues that generated mission risk and uncertainties. For example, the small size of the target asteroid makes that class of object extremely difficult to find and observe to determine if it possesses an Earth crossing orbit with proper phasing. It is also difficult to determine the size and composition of the body and thus its mass. The high uncertainty implied an associated high probability of mission failure because it was possible that the mission could arrive at its target and find a body that was too large, too massive, had an unacceptably high set of spin rates, or was too friable (loosely gathered rubble pile) for the capture system to accommodate. As a result, an internal NASA study was performed to assess the feasibility of a mission where a spacecraft would visit a large NEA, i.e. with a diameter at least 100 meters, and return a boulder (in the 1 - 10 meter diameter range) to a stable lunar vicinity orbit. An additional feature of this mission would be to use the combination spacecraft/boulder mass to perturb the parent asteroid trajectory as a planetary defense demonstration. By providing a larger range of target asteroids, and enabling a boulder to be selected once at the destination, this concept had the potential to greatly reduce the mission risk. In subsequent discussions, the original mission has been referred to as Asteroid Mission Concept A, and the "pick up the boulder" approach as Asteroid Mission B.

In June of 2013, NASA issued a Request for Information ${ }^{3}$ (RFI) to gather innovative ideas that could be used to plan the Asteroid Redirect Mission (ARM)). The RFI sought information on all aspects of the mission and solicited ideas that pertained to both mission concepts $\mathrm{A}$ and $\mathrm{B}$. The results of the RFI were reviewed at two workshops and incorporated into a final report ${ }^{4}$. A number of alternative concepts were proposed for the Mission Concept A capture system that sought to improve the probability of mission success as well as mission versatility. Due to the large number of uncertainties with both mission concepts A and B, many of which might not be resolved until the spacecraft arrives at its destination, it can be argued that mission success can be maximized by incorporating a versatile and reusable asteroid capture system that is able to 
accommodate many different mission scenarios. By including in that system a capability to also enable and support astronaut crew operations at the asteroid in cis-lunar space, mission affordability will also be enhanced.

The concepts described in this paper, to retrieve all or a portion of an asteroid, are based on and leverage the capabilities of a new and novel Tendon-Actuated Lightweight In-Space MANipulator (TALISMAN) system ${ }^{5}$. The TALISMAN (manipulator-based) approach has the primary goal of dramatically increasing the versatility of the asteroid capture/enclosure system, allowing it to not only capture a free flying asteroid, but also accommodate many other possible mission scenarios involving larger asteroid bodies. This operational versatility would maximize the possibility of mission success by increasing the likelihood of securing material once at the target asteroid. For a mission to a large asteroid, the TALISMAN-based concept would enable a number of different scenarios, such as: acquiring a single large boulder (the boulder could be "loose" and plucked from the surface, or end effectors could be used to cut, pry, dislodge or excavate a more firmly attached boulder); acquire a number of smaller boulders from the surface in the event that one large boulder is not easily acquired or desired; or fill compartments of a capture bag with loose material from one or more sites on the asteroid's surface using an excavation end effector if loose material is desired.

\section{Asteroid Redirect Mission Description and Requirements}

In March of 2014, NASA released a Broad Agency Announcement (BAA) pertaining to the Asteroid Redirect Mission ${ }^{6}$ seeking proposals for system concept studies, technology development activities and partnership opportunities to support the goals of the Asteroid Initiative. The Announcement stated that NASA is developing two mission Concepts for the ARM; Concept A uses a robotic spacecraft to capture a whole small NEA, and Concept B uses essentially the same robotic spacecraft to capture a cohesive mass from a larger asteroid. Illustrations of the two concepts using capture systems based on long reach TALISMAN systems are presented in Figs. 1 and 2. In both mission cases, the asteroid/material is brought back to cislunar space where astronauts would rendezvous with the spacecraft and asteroid and take samples and perform science experiments. A summary of the two mission options and their requirements, particularly those that pertain to the Asteroid Capture System (ACS) are summarized here.

\section{Option A: Capture a Whole Small NEA}

In Option A, key challenges are capturing and despinning the asteroid relative to inertial space. The task is made much more difficult due to the uncertainties in the asteroid mass, shape, spin rate and composition (solid body versus loose conglomeration of material, or rubble pile). These uncertainties are likely to persist up until the time the mission spacecraft reaches the asteroid vicinity. In this option, the ACS must be able to accommodate relative motion and irregular asteroid shapes until the capture process is complete.

Key assumptions and requirements for Option A are ${ }^{6}$ :

- Assume that the spacecraft will match the spin rate such that there remains a residual surface velocity of $<1 \mathrm{~cm} / \mathrm{sec}$. 
- Asteroid mean diameter is between 4 and 10 meters.

- Asteroid maximum diameter is 13 meters.

- Asteroid mass is between 100 - 1,000 metric tons.

- Maximum asteroid rotation rate is 0.5 revolutions per minute.

- The asteroid composition, internal structure and physical integrity will likely be unknown until after rendezvous and capture.

- The asteroid material must be accessible by extra-vehicular activity (EVA) astronauts.

\section{Option B: Retrieve a Single Boulder From a Larger Asteroid}

A key feature of Option B is to reduce uncertainty and mission risk. In this concept, NASA desires to use autonomous robotic systems to retrieve and firmly restrain a cohesive boulder-like mass from the surface of a larger (and easier to find and characterize) asteroid. Although the boulder will be characterized prior to capture operations, its precise friability will likely be unknown until the capture process is underway.

Key assumptions and requirements for Option B are :

- Boulder size is $1-5$ meters in any dimension.

- Capture system scalable to larger boulders, up to 10 meters.

- Boulder mass up to 30 metric tons, but up to 1,000 metric tons for 10 meter size.

- Boulder assumed to be coherent with compressive strength of at least 0.3 MPa.

- Design must account for the forces needed to overcome cohesion and separate the boulder from the asteroid's surface.

- System should be tolerant of possible boulder break-up during the capture process by being able to release the boulder without damaging the capture system.

- System should be capable of multiple attempts to capture a boulder.

- Assume parent asteroid rotation rate of up to 0.33 revolutions per hour about any or all axes, with up to 1.0 revolution per hour also of interest.

- The asteroid material must be accessible by EVA astronauts.

\section{TALISMAN Description}

The current state-of-the-art (SOA) in long-reach space robotic manipulators is represented by the International Space Station Remote Manipulator System (SSRMS) and the Shuttle Remote Manipulator System (SRMS), which is now out of service. The SRMS uses a traditional manipulator architecture that consists of lightweight booms connected by massive rotary joints that are systems of motors, gearboxes and brakes. The rotary joints account for 85 to 90 percent of the manipulator mass and manipulator compliance (in response to an applied load ${ }^{5}$ ). The long booms result in restrictive packaging options, and adding joints to improve packaging would incur an extremely high mass penalty. The high mass associated with the joints in this conventional architecture results in practical limits to: reach, packaging, stiffness and tip force that can be achieved.

\section{Overview of New Features and Benefits}

In order to enable future missions and applications it is desirable to improve space manipulator 
SOA (represented by the SRMS) by significantly increasing manipulator reach and dexterity while reducing manipulator mass and packaging volume. The TALISMAN is an invention (patent application has been filed) of a new robotic manipulator architecture that incorporates a tendon-actuated joint with a novel hinge that allows a full 360-degree rotation between connecting links and the capability to incorporate auxiliary structural tension stiffening. Tendon actuation incorporates spreaders to achieve longer moment arms between the force applied by tendons and the joint rotation axis, thus gaining mechanical advantage for generating moments and actuating the joints. An overview of the TALISMAN is shown in Fig. 3, and a detailed description of its architecture, features, options and performance is contained in reference 5.

Key features of the new TALISMAN architecture and approach are:

- Uses tendon actuation, which can be semi- or fully-antagonistic, with major components being the link, spreader, lightweight cables, motors and gearboxes,

- Increased joint stiffness due to tendon architecture,

- $\quad$ Lightweight joints enable the number of joints to be optimized to achieve desired packaging efficiency, range-of-motion, dexterity, etc.,

- $\quad$ Potential to increase manipulator stiffness using passive tension elements (very lightweight),

- Versatility; many different cable/motor/control options can be implemented,

- Modularity; links and joints are easy to scale for different applications, can combine link and joints as needed for packaging, dexterity, etc. to achieve operational needs,

- $\quad$ Novel hinge joint allows full 360-degree rotation between adjacent links, improving dexterity and range of motion,

- Uses lightweight truss structures for links.

\section{Structural Sizing and Mass Estimation Summary}

The TALISMAN architecture is characterized by its structural simplicity and efficiency. This is realized by using a modular, and periodic tension-compression design (see Fig. 3) that also lends itself to analytical modeling. Closed-form, parametric equations were derived for sizing the three primary structural members (truss links, spreaders and tendons, see Fig. 3c) based on applied loads and tip deflection constraints and used in a rapid design spreadsheet described in Doggett et $\mathrm{al}^{5}$. This spreadsheet-based design tool produced conservative structural mass estimates and sizing for a fully extended TALISMAN (as depicted in Fig. 3a) with each set of arm links, spreaders and tendons required to have identical geometries. The closed-form analytical equations required these limitations in order to be simple enough to be incorporated into a spreadsheet-based tool. The equations did not include an applied axial tip load and the maximum induced load in each set of primary structural members was used for sizing all of the members in that set.

In order to take full advantage of the TALISMAN architecture and all of its innovative features, a more sophisticated analysis that can perform full structural optimization was needed. Recent mission studies required these optimization analyses in order to provide more accurate estimates of TALISMAN system performance and mass. As a result, a new and more sophisticated design and sizing tool has been created in MATLAB and is used for the sizing cases presented in this paper. This new tool for TALISMAN goes well beyond the previous spreadsheet design tool ${ }^{5}$ 
that was primarily used for initial design and parameter space investigation. The new tool allows the input of variable geometry and configurations in multiple poses. Forces can be applied anywhere on the nodal model and in any direction. It can perform a large number of parametric analyses within a few minutes due to its low computational time. It also improves the display of results; plotting the actual deformed and sized geometry with stresses, and outputting a data file that contains all test runs and parameterized sizing results. Masses for additional components in the manipulator (joints, motors, gearboxes, electronics, sensors etc.) have also been estimated and are calculated externally to the MATLAB tool, and can now be easily integrated. This new tool enables the TALISMAN architecture to be rapidly adapted and optimized to a wide range of applications while also providing a high degree of confidence in the structural performance and system mass estimation results. This new sizing tool can be run in three different modes: a) sizing for a single configuration (pose) with a plot displaying the deflections, stresses and actual member sizes superimposed on the pose (two examples shown in Fig. 4); b) sizing for an operational range of poses (as shown in Fig. 5, for illustration), where only the sizing parameters are calculated but no results are plotted (to increase computational speed); and, c) plotting only the poses of previously run sizing cases to superimpose multiple runs (Fig. 6).

\section{Technology Status}

The technology for the TALISMAN is being developed within the NASA Space Technology Mission Directorate's Game Changing Development (GCD) Human Robotics Systems (HRS) project. By September of 2013, the critical elements of a first generation TALISMAN prototype section were fabricated, assembled and simple articulation of a single hinge joint tested. The designs for the aluminum truss links, motor/gearboxes, hinge-joint/spreader system and cables were notionally based on emulating a SRMS-class manipulator ${ }^{5}$. With this prototype joint system, full 360-degree hinge joint rotation was demonstrated using an active-passive version of the tendon (1.58 mm diameter steel cables) actuation system. Lessons learned from testing the hardware system, combined with the rapid analysis/sizing capability described in the previous section informed the design of a second generation TALISMAN system.

Currently, two second-generation TALISMAN prototypes are being assembled in the laboratory, as shown in Fig. 7. The facility has a large-area flat floor that serves as an air bearing surface and air bearings are mounted to both TALISMANs allowing zero gravity operations to be simulated in the plane of the floor. The second generation TALISMAN use the same aluminum truss design for the links as were used in the first generation system. However, the hingejoint/spreader system has been redesigned to provide greater stiffness, buckling strength and new operational modes. The gearboxes have been redesigned to transmit higher loads, be much less susceptible to structural and operational failures and accommodate a $3.18 \mathrm{~mm}$ diameter cable (thus allowing the manipulator to generate higher tip force). A manipulator control system, that accommodates both joint and end-point control modes, was developed under contract, has been installed and is currently being checked out. New motors (that drive the new gear boxes), tension sensors (to measure cable tension in each bay), joint angle sensors and motor control electronics have all been installed on the two new prototypes. Data from the tension and joint angle sensors and the motor controllers are all monitored by the control system and used to position each TALISMAN. 
The two TALISMANs are attached to a large steel plate that represents a spacecraft bus and the plate is also supported by air bearings allowing a free-free spacecraft with two manipulators to be simulated in experiments. The distance between the bases of the two TALISMANs can be adjusted and are 2.9 meters apart in the configuration shown in Fig. 7, which is very representative of the diameter of the ARM (and other) spacecraft bus, so the configuration accurately represents a full-scale system. Each TALISMAN has three degrees of freedom (dof) and three 3.66-meter-long links. Adding the short 0.57 meter-long stub at the base, gives each manipulator a total length of 11.55 meters. Adding a fourth link (which would also add one dof) would give a total length of 15.2 meters and result in a SRMS-class manipulator. Although the SRMS configuration can easily be assembled from parts on hand, the resulting span leaves little space to conduct operations. Thus, the dual 3-link TALISMAN setup will be used extensively to develop and test operational scenarios.

\section{TALISMAN Technology Versatility}

\section{General Versatility}

Long-reach robotic manipulation is a critical capability that NASA developed for both Space Shuttle (Shuttle RMS - SRMS) and International Space Station (ISS) operations (Space Station RMS - SSRMS). Having the versatility of a general purpose manipulator successfully enabled a wide variety of operations such as; satellite servicing, Hubble repair and servicing, EVA positioning, ISS assembly, berthing of resupply spacecraft at ISS, and robotic manipulator positioning (DEXTRE) on ISS to support research and maintenance operations. However, the SRMS and SSRMS both required the Space Shuttle to launch them into orbit (they were attached, fully extended to the sill of the 60-foot long Shuttle cargo bay). When the Space Shuttle retired, the US completely lost the capability to launch these conventional type of long-reach robotic manipulators into space and replace, maintain or increase this critical capability. These conventional manipulators cannot simply be packaged more efficiently to fit within the more confined cargo spaces of current launch vehicles, because additional joints would have to be added to allow shorter link lengths. Conventional manipulator joints are extremely heavy, with the joints of the SRMS representing $\sim 90 \%$ of the total manipulator mass ${ }^{5}$, so adding joints to increase packaging efficiency results in unacceptable mass growth. In addition, the stiffness, fundamental vibration frequency and tip force capability of these conventional manipulators all degrade quickly with increases in mass and/or reach. The TALISMAN not only maintains the versatility of traditional long-reach space manipulators, it increases versatility be providing the capabilities for increased packaging efficiency, increased reach, increased stiffness and reduced mass.

\section{Versatility for Asteroid Redirect Missions}

Many of the proposed solutions for asteroid retrieval require significant technology development, but result in systems that address only one specific implementation of a mission concept and have no long-term applicability to future NASA missions. The TALISMAN technology, as applied to the Asteroid Redirect Mission concepts, has the primary goal of dramatically increasing the versatility of the asteroid capture/enclosure system allowing it to not only capture a free flying asteroid (Mission Concept A), but also accommodate many other possible mission 
scenarios involving larger asteroid bodies (Mission Concept B for example). This versatility would maximize the possibility of mission success by dramatically improving the likelihood of securing material once at the target asteroid.

In addition to mission versatility, having general-purpose manipulators with an appropriate suite of tools and end effectors would dramatically increase operational versatility. The TALISMAN and a properly designed set of end-effector tools could perform the following asteroid-mission functions: surveying and imaging, sample collection (drilling, scooping, scraping) and characterization, payload manipulation and precision positioning (including sensors, instruments, astronauts and EVA tools), landing/docking and holding spacecraft in position, facilitating deployment of a containment bag, capture and de-spin of either all or part of the asteroid material, facilitation of asteroid trajectory changes (planetary defense demonstrations), and support of EVA operations after asteroid return. Functional versatility also provides a means for addressing off-nominal situations and contingencies. Such situations could range from acquiring a surface sample or image prior to critical operations, to completely separating from an asteroid and redocking in order to repeat a failed capture attempt. A versatile system can also accommodate multiple (and evolving) mission success criteria. A system comprised of more than one manipulator provides system redundancy because many operations can be performed without all manipulators functioning.

\section{Preliminary Design and Sizing Results}

\section{SRMS-Class Manipulator}

The technology for the as-built TALISMAN (described previously) is being developed to specifications that are representative of an SRMS-class space manipulator. The specifications for the as-built TALISMAN and the mass of the associated hardware are used to inform and estimate the mass of the capture system concepts designed in this paper for the Asteroid Redirect Mission. The design specifications for the as-built TALISMAN are summarized under the SRMS-class results presented in Table 1. This as-built prototype configuration has the reach of an SRMS and can apply the SRMS tip force, but does not meet the deflection (stiffness) constraint that is also imposed on the SRMS. Constraints for tip deflection and a small transverse load are added to the as-built sizing, resulting in the aluminum and polymeric composite (PMC) versions also listed in Table 1 . The as-built TALISMAN is an active-passive implementation, which means that only the cables on one side of the manipulator are actively driven by the motor/gearbox system. Every other implementation given in the table assumes an active-active tendon drive system, meaning that the cables on both sides of the manipulator are driven by individual motor-gearbox systems. Although the number of gearboxes is identical for both implementations, the number of motors in the active-active implementation is double that of the active-passive implementation. The active-active implementation is chosen for all of the applications because of its; capability to apply larger and symmetric forces, ability to zero-out tip deflections, and ability to perform active vibration damping.

The aluminum and PMC implementations of the SRMS-class TALISMAN are given to illustrate the relationship and provide traceability between actual prototype hardware (the as-built system) mass and mass estimates for the ARM concepts. Table 2 gives a complete listing of all hardware 
needed to assemble a TALISMAN, as well as the mass of each component for each system implementation. A 30\% factor is added to the subtotal component mass estimate, to account for mass growth that normally occurs as a technology progresses from prototype to flight, to obtain the final total estimated mass. The aluminum implementation has a mass that is slightly smaller than the as-built system primarily due to the reduction in truss link mass because the as built trusses were not optimized. The mass of the motors in the aluminum implementation is double that of the as-built, reflecting the change to an active-active tendon actuation system. The mass of the cables are also greater because their area was increased to increase stiffness to meet the deflection constraint. The mass of the control boxes (small to begin with) are reduced in the aluminum flight system to reflect going from off-the-shelf industrial motor control boxes to customized electronics. Significant structural mass reduction occurs when going from the aluminum to the PMC SRMS implementation, due to the increase stiffness and reduced density of the composite materials in the truss links and spreaders. In addition, polymeric material is assumed for the tendons, increasing stiffness over steel cables, while also reducing material density resulting in significantly reduced cable mass. Compared to reference 5, the mass estimate for the PMC SRMS-class TALISMAN in Table 2 includes a more complete and detailed list of equipment, as well as more accurate masses that are informed by as-built hardware. Thus, the mass calculated in this paper is $75 \%$ greater than the mass estimated in reference 5 . However, the total of $63.35 \mathrm{~kg}$ is still 15\% of the SRMS mass ${ }^{5}$, and illustrates the significant advantage offered by the TALISMAN technology.

\section{Asteroid Mission Concept A}

\section{Capture System Description and Operations Concept}

The asteroid material capture system consists of two major subsystems; a set of three TALISMANs and a simple lightweight Enclosure Bag (EB) made from textile soft goods. The capture system is assumed to integrate with the solar electric spacecraft bus at a circular interface, with the diameter of the interface being 3 meters. The 3 TALISMANs are attached along the outside edge of the interface at 120-degree intervals and each TALISMAN has four truss links and four tendon-actuated hinge joints. The base of each TALISMAN is mounted to a simple turntable, providing a fifth (rotary) degree of freedom. The four links are folded for launch so that the packaged TALISMANs easily fit into the baseline launch vehicle (Atlas V) medium or long payload shroud. The enclosure bag is attached to the circular interface structure at its base and folded in the launch vehicle in the center portion of the space between the stowed TALISMANs. The packaged system is shown in Fig. 8. The EB has a simple inflatable ring integrated at its open end that is inflated to provide a large circular opening for acquiring an asteroid. The system has redundancy since the mission can be successfully completed even if one of the TALISMANs completely fails to operate.

The steps in a general concept of operations (ConOps) are:

\section{Eliminate Asteroid Tumbling Motion}

- $\quad$ Three TALISMANs and EB are packaged for launch and remain packaged during transit to the asteroid, as shown in Fig. 8.

- $\quad$ In the vicinity of the asteroid, the 3 TALISMANs deploy their 4 links (see Fig. 9).

- $\quad$ Spacecraft flies to vicinity and matches asteroid major rotation. 
- One or more TALISMANs grapple the asteroid.

- Spacecraft fires thrusters to eliminate asteroid rotations, then TALISMANs release asteroid.

2. Deploy the EB

- From their poses at the end of step 1 (Fig. 10), the 3 TALISMANs acquire 3 grapple fixtures that are located on the EB opening, as shown in Fig. 11.

- 3 TALISMANs pull the EB away from the spacecraft interface until the bag is at full extension.

- The EB opening ring is inflated resulting in the fully deployed configuration, as shown in Fig. 12.

3. Capture Free-Flying Asteroid (after relative motion has been eliminated)

- Spacecraft slowly approaches and translates until the asteroid is fully inside the EB envelope (Fig. 1).

- The circular opening ring is deflated.

- Three TALISMANs close and secure EB opening, grapple asteroid (through the EB), move it to its final position (one where the asteroid cg is aligned with the vehicle thrust axis), and secure it firmly in place against the spacecraft for return trip.

\section{System Sizing and Mass Estimate}

Two different total lengths, 16 and 20 meters, were selected for the TALISMAN in Mission Option A to account for changes in the asteroid size and shape as the mission definition has progressed. Both options have 4 truss links, 5 dof and were sized to the same applied tip force, as listed in Table 1 . They were also both designed to have a tip deflection of $1 \%$ of the total length when subjected to the applied tip load. Due to its greater length, the 20-meter TALISMAN, at $78.04 \mathrm{~kg}$, has a higher mass than the 16 -meter (at $65.76 \mathrm{~kg}$ ). During an internal study, the mass of the enclosure bag was estimated to be $59.2 \mathrm{~kg}$. Thus the mass of a complete Mission Concept A capture system (three TALISMANs and enclosure bag) would be $256.5 \mathrm{~kg}$ for a system with 16-meter reach and $293.3 \mathrm{~kg}$ for a system with 20-meter reach. Detailed mass estimates for TALISMAN hardware components are given in Table 2. The system with 20-meter reach is illustrated in figure 1.

\section{Asteroid Mission Concept B}

\section{Capture System Description and Concept of Operations}

When the ARM was first proposed and studied there was no Mission Option B. At that time, the TALISMAN concept described in the previous section was developed and sized. The concept of retrieving a boulder off of a large asteroid was discussed and in order to demonstrate the versatility of the TALISMAN concept, it was shown how that concept, without any modifications could be applied to the "pick up a boulder" scenario (see Fig. 13). Eventually, NASA performed formal mission studies of Option B, where a number of boulder capture system concepts were developed and evaluated. Currently, the preferred capture system is described as a hybrid of the options considered in the formal study and incorporates 2 dexterous grapple arms and 3 simple space-frame landing legs (see Fig. 14). The space frames have 3 dof 
each and serve as landing and push-off legs for the spacecraft. The space frame does not have the capabilities of a general-purpose manipulator, rather, it has very limited dexterity and range-ofmotion and functions as landing gear for the spacecraft. The spacecraft approaches the asteroid at a specified terminal velocity, the three space frames make contact with the surface, and then they articulate through a limited range of motion to decelerate the spacecraft. The space frames must have sufficient length to span the boulder and still provide clearance at the end of the deceleration stroke, as shown in Fig. 14. The space frames also provide an initial departure velocity to the spacecraft upon departure of the spacecraft/boulder system from the asteroid. The space frames, as opposed to the spacecraft thrusters, are used to achieve initial velocity to avoid the possibility of the thruster exhaust ejecting particles from the asteroid that might cause damage to the large solar arrays or other spacecraft components. The two grapple arms are dexterous manipulators, used to grasp the boulder after the space frames have lowered the spacecraft into a crouching position. The grapple arms are shorter than the space frames and only need to reach around and grab the boulder to pluck it from the surface (as shown in Fig. 14). They then lift the boulder up against the spacecraft and secure it there for the rest of the mission.

The lengths and structural performance of the space frames and capture arms are dictated by the size of the boulder being grasped and the gravitational constant of the parent asteroid; the larger the gravitational value, the smaller the mass (and thus boulder size). Internal NASA studies have looked at a variety of parent asteroids, including the moons of Mars (Phobos and Deimos). For example, for the asteroid Itokawa, with gravity of $0.0001 \mathrm{~m} / \mathrm{sec}^{2}$, the spacecraft could retrieve a boulder approximately 4 meters in diameter and with a mass of 70,000 kg. From Phobos, where gravity is $0.057 \mathrm{~m} / \mathrm{sec}^{2}$, the spacecraft could retrieve a boulder approximately 1 meter in diameter with a mass of $4,600 \mathrm{~kg}$.

As Mission Concept B has become more refined, a specific TALISMAN-based system was developed to parallel the baseline system ConOps (see Fig. 2). Two different TALISMAN embodiments make up the capture system: one that is sized for the landing stroke, boulder clearance and achieving a push-off velocity; and one that is sized to grapple, hold and secure a boulder. The three larger TALISMAN landing legs are attached to the spacecraft bus and spaced at 120 degrees. They each have 3 links and 3 single-dof hinge joints (with full range of motion), with the first joint at the base. In order to provide additional dexterity and support EVA operations, a rotary joint is also added at the base of each landing leg. Three smaller TALISMAN are sized to serve as dexterous manipulators for handling the boulder. These manipulators are also located on the spacecraft bus, spaced at 120 degrees and mid-way between the landing legs. Two versions of the manipulators were sized to evaluate reach and dexterity requirements; one with three links (and three dof) and one with 4 links (and four dof). The most severe loads on the manipulators occur for the conditions of landing on, departing from, and plucking a boulder off of the surface of Phobos, so the TALISMAN capture system designed to those conditions is presented.

The versatility of the TALISMAN capture system developed for mission concept A, when directly applied to mission concept B would enable many different scenarios:

1. If the boulder is "loose" it could be plucked from the surface, enclosed and returned. If the boulder is firmly attached to the larger body (but is still a separate boulder, not the top 
of a much larger boulder) end effectors could be used to cut, pry, dislodge or excavate the boulder.

2. In the event that one large boulder is not easily acquired or desired, a number of smaller boulders could be acquired from the surface. These boulders could be adjacent to each other, or could be acquired from different sites around the asteroid. Each boulder can be placed in an isolated compartment to prevent cross-contamination of the samples if desired.

3. In addition, an excavation end effector could simply fill the capture bag or a compartment of the bag, with loose material from one or more sites. If desired, the bag could be designed to have multiple compartments allowing material to be acquired from different locations on the asteroid without mixing.

4. The system could be used to perform sample inspection prior to storage, allowing low value or redundant samples to be rejected.

5. The system could be used to emplace scientific instruments for asteroid monitoring.

Example ConOps for applying Capture System Concept A directly to Mission Concept B include the following:

- Acquire One Large Boulder from a Parent Asteroid; one TALISMAN grabs and secures spacecraft to parent asteroid while other two TALISMANs use appropriate end effector to either; pick boulder off surface, pry boulder loose from surface, or cut boulder loose from surface (diamond wire saw for example) and place boulder inside EB.

- Acquire Several Smaller Boulders from a Parent Asteroid (depicted in Fig. 13); one TALISMAN grabs and secures vehicle to parent asteroid, while one or two TALISMANs use appropriate end effector to either; pick boulders off surface, pry boulders loose from surface, or cut boulders loose from surface (diamond wire saw for example) and place boulders inside EB.

- Acquire Loose Material from a Parent Asteroid; one TALISMAN grabs and secures spacecraft to parent asteroid, while a second TALISMAN uses appropriate end effector to continuously dig/scoop/excavate material from surface and deposit material inside EB until sufficient material has been acquired.

- Options for Acquiring Multiple Boulders and Loose Material; if samples are desired from different locations on the large asteroid, two of the TALISMANs can be used to walk the system around the body while the third TALISMAN acquires samples.

The concept of operations for the TALISMAN system designed specifically for Mission Concept B entails:

- The three landing leg and grapple arm TALISMAN are packaged for launch and remain packaged during transport to the asteroid vicinity.

- In the vicinity of the large asteroid, all of the TALISMAN deploy into their operational configuration.

- The spacecraft performs initial reconnaissance at the asteroid, identifying and prioritizing boulder targets.

- After boulder selection, the spacecraft begins descending towards the surface, keeping the boulder centered within the landing legs and grapple arms (Fig. 15).

- The landing legs make contact with the asteroid surface (Fig. 16) at three locations. 
- The landing legs articulate and decelerate the spacecraft to zero velocity, while maintaining 1-meter clearance between the boulder and all spacecraft/TALISMAN surfaces (Fig. 17).

- The landing legs articulate further to crouch the spacecraft so that it is no closer than 0.5 meters from the boulder and the grapple arms reach around and grasp three points on the boulder underside (Fig. 18).

- The grapple arms apply upward force, breaking the cohesive bond between the boulder and asteroid, raise the boulder and position it against the spacecraft interface (Fig. 19). The boulder center-of-gravity is aligned with the spacecraft thrust axis during this time.

- The landing legs begin articulating to accelerate the spacecraft upward (Fig. 20), reaching full extension and maximum velocity (Fig. 21) and propelling the spacecraft off of the asteroid surface (Fig. 22).

\section{System Sizing and Mass Estimate}

The Mission Concept B TALISMAN design specifications for picking up a boulder on Phobos are given in Table 1. The three landing legs each have three 1.5-meter-long links and 4 dof (three hinge joints and rotary joint at spacecraft interface). The legs are designed primarily for the surface contact load induced by decelerating the spacecraft at landing and accelerating the spacecraft with retrieved boulder at departure. A stroke length of 1.0 meter is assumed for both cases to derive the applied force. An out-of-plane side load, assumed to be $10 \%$ of the deceleration/acceleration load, is applied to account for any transverse forces induced by an uneven landing surface. The mass of each landing leg system is estimated to be $35.4 \mathrm{~kg}$ (Table 2).

The three grapple arms are designed to grasp the boulder on its underside at points approximately 45 degrees between the equator and its contact point (see Fig. 19). Because the boulder can have an irregular shape, two versions of the grapple arms were sized. Version one has longer reach (3.0 meters), higher dexterity (4 links with 5 dof), and can accommodate shapes that are more irregular. Version two has shorter reach (2.5 meters), three links (two at 1.0 meters and one at 0.5 meters) and 4 dof. The two versions of the grapple arms are shown in their boulder contact poses in Fig. 4. The grapple arms are designed to react the load of the boulder induced by the acceleration of the spacecraft from the surface as well as the load induced by a visiting spacecraft docking maneuver once the ARM spacecraft returns to cis-lunar space. An out-of-plane side load, assumed to be $10 \%$ of the deceleration/acceleration load, is applied to account for any transverse forces induced by irregularities in the boulder surface. The estimated mass of the shorter, less dexterous grapple arm is approximately $25 \%$ less than that of the longer arm; $14.6 \mathrm{~kg}$ versus $19.3 \mathrm{~kg}$ (Table 2). The small additional mass to achieve higher dexterity and a larger reach envelope with the longer grapple arm may be a good investment because of the likely increase in mission success it provides. The total system mass for a TALISMAN-based mission concept B capture system, consisting of three landing legs and three grapple arms, would be $164.1 \mathrm{~kg}$ for the longer grapple arms, and $150.0 \mathrm{~kg}$ for the shorter grapple arms (Table 2).

\section{Concluding Remarks}

The mission to retrieve either a complete small-body asteroid (Mission Concept A), or a boulder off of a large asteroid body (Mission Concept B) is receiving high priority and being investigated by NASA. However, there is currently a great deal of uncertainty as to which mission will 
ultimately be chosen by NASA as well as the viability of proposed asteroid capture systems. For both mission concepts, there is also a great deal of uncertainty associated with the sample being retrieved, including the sample's size, mass, shape (degree of irregularity), spin rate, composition, friability, and adhesiveness to the surface. Because this uncertainty may not be resolved until the target asteroid is reached, it will be extremely difficult and high risk to design special-purpose capture systems (the current NASA approach) that can accommodate many of the off-nominal scenarios likely to be encountered. Thus, it may also prove difficult to achieve a high degree of predicted mission success.

The TALISMAN is a new technology for general-purpose long-reach space manipulators. Because manipulators provide a great deal of operational versatility, designing capture systems that incorporate manipulators results in a system that dramatically increases the chances for mission success. By including a versatile suite of tools and end-effectors, the TALISMAN-based asteroid capture system provides the capability to handle many potential scenarios once at the target asteroid, even those not specifically anticipated. The high degree of versatility inherent in the TALISMAN-based system is proven by applying a capture system designed for mission concept A directly to mission concept $\mathrm{B}$, with no changes to the capture system. The versatility of the TALISMAN technology is demonstrated by designing landing-leg and grapple-arm systems specifically to meet the mission concept B requirements. The low mass of TALISMANbased capture systems; 256.5 - $293.3 \mathrm{~kg}$ for mission concept A, and $150.0-164.1 \mathrm{~kg}$ for mission concept B makes them extremely competitive options to consider for these missions. Finally, since developing the TALISMAN for the ARM results in a general robotic capability that can be directly applied to other missions (including satellite servicing and repair, on-orbit assembly, EVA positioning and spacecraft berthing), significant cost savings could be accrued by other critical NASA missions.

\section{References}

1. Brophy, J. R., and L. Friedman, May 22-24, 2012: Returning an Entire Near-Earth Asteroid in Support of Human Exploration Beyond Low-Earth Orbit. 2012 Global Space Exploration Conference.

2. Asteroid Redirect Mission Feasibility Study Final Report. May 24, 2013, Version 2.0. Jet Propulsion Laboratory.

3. Request for Information for NASA's Asteroid Initiative, Solicitation Number NNH13ZCQ001L, June 18, 2013, https://prod.nais.nasa.gov/cgibin/eps/synopsis.cgi?acqid=156731.

4. Asteroid Initiative Ideas Synthesis Workshop, Final Report, January 2014. POC: Dr. Chris Moore, NASA HQ.

5. Doggett, William R.; Dorsey, John T.; Jones, Thomas C.; and King, Bruce: Development of a Tendon-Actuated Lightweight In-Space MANipulator (TALISMAN). Proceedings of the $42^{\text {nd }}$ Aerospace Mechanisms Symposium, NASA Goddard Space Flight Center, May 14 - 16, 2014.

6. Asteroid Redirect Mission Broad Agency Announcement; OMB Approval Number 27000085, Broad Agency Announcement NNH14ZCQ002K. Release Date: March 21, 2014. 
Table 1. TALISMAN design specifications.

\begin{tabular}{|l|c|c|c|c|c|c|c|c|}
\hline \multirow{2}{*}{ Specification } & \multicolumn{4}{|c|}{ SRMS Class } & \multicolumn{2}{c|}{$\begin{array}{c}\text { Mission } \\
\text { Concept A }\end{array}$} & \multicolumn{3}{c|}{$\begin{array}{c}\text { Mission Concept B - } \\
\text { Phobos }\end{array}$} \\
\cline { 2 - 9 } & $\begin{array}{c}\text { As- } \\
\text { built }\end{array}$ & Al & PMC & $\begin{array}{c}\text { PMC } \\
\text { 16-m }\end{array}$ & $\begin{array}{c}\text { PMC } \\
\text { 20-m }\end{array}$ & $\begin{array}{c}\text { PMC } \\
\text { Leg }\end{array}$ & $\begin{array}{c}\text { PMC } \\
\text { Arm-1 }\end{array}$ & $\begin{array}{c}\text { PMC } \\
\text { Arm-2 }\end{array}$ \\
\hline Total length, m & 15.24 & 15.24 & 15.24 & 16.0 & 20.0 & 4.5 & 3.0 & 2.5 \\
\hline Number of links & 4 & 4 & 4 & 4 & 4 & 3 & 4 & 3 \\
\hline Link length, m & 3.81 & 3.81 & 3.81 & 4.0 & 5.0 & 1.5 & 0.75 & $0.5-1.0$ \\
\hline Number of dof & 5 & 5 & 5 & 5 & 5 & 4 & 5 & 4 \\
\hline Design deflection, m & NA & 0.038 & 0.038 & 0.16 & 0.20 & NA & NA & NA \\
\hline Design load, $F_{x}-\mathrm{N}$ & 0.0 & 0.0 & 0.0 & 0.0 & 0.0 & 4620.0 & 883.4 & 883.4 \\
\hline Design load, $\mathrm{F}_{\mathrm{y}}-\mathrm{N}$ & 66.7 & 66.7 & 66.7 & 66.7 & 66.7 & 0.0 & 0.0 & 0.0 \\
\hline Design load, $\mathrm{F}_{\mathrm{z}}-\mathrm{N}$ & 0 & 6.7 & 6.7 & 6.7 & 6.7 & 462.2 & 88.3 & 88.3 \\
\hline Spreader height, m & 2.0 & 2.0 & 2.0 & 0.8 & 1.0 & 0.6 & 0.3 & 0.3 \\
\hline
\end{tabular}

Table 2. TALISMAN mass estimates.

\begin{tabular}{|l|c|c|c|c|c|c|c|c|}
\hline \multirow{2}{*}{ Item/Mass, kg } & \multicolumn{3}{|c|}{ SRMS Class } & \multicolumn{2}{c|}{$\begin{array}{c}\text { Mission } \\
\text { Concept A }\end{array}$} & \multicolumn{3}{c|}{$\begin{array}{c}\text { Mission Concept B - } \\
\text { Phobos }\end{array}$} \\
\cline { 2 - 9 } & $\begin{array}{c}\text { As- } \\
\text { built }\end{array}$ & Al & PMC & $\begin{array}{c}\text { PMC } \\
\mathbf{1 6 - m}\end{array}$ & $\begin{array}{c}\text { PMC } \\
\mathbf{2 0 - m}\end{array}$ & $\begin{array}{c}\text { PMC } \\
\text { Leg }\end{array}$ & $\begin{array}{c}\text { PMC } \\
\text { Arm-1 }\end{array}$ & $\begin{array}{c}\text { PMC } \\
\text { Arm-2 }\end{array}$ \\
\hline Truss links & 20.00 & 8.52 & 3.65 & 5.73 & 7.37 & 3.99 & 1.05 & 0.83 \\
\hline Spreaders & 10.40 & 10.02 & 6.17 & 2.63 & 3.22 & 1.53 & 0.75 & 0.56 \\
\hline Cables & 2.30 & 5.53 & 1.31 & 3.41 & 4.24 & 4.97 & 0.62 & 0.40 \\
\hline Link Hinges & 2.40 & 2.40 & 2.40 & 2.40 & 2.40 & 1.80 & 1.20 & 0.90 \\
\hline Base Rotary Joint & 1.99 & 1.99 & 1.99 & 1.99 & 1.99 & 1.99 & 0.99 & 0.99 \\
\hline Take-up Spring Sys. & 8.38 & 4.79 & 4.79 & 4.79 & 4.79 & 3.59 & 2.40 & 1.80 \\
\hline Motors & 6.32 & 12.64 & 12.64 & 13.27 & 16.59 & 2.66 & 2.49 & 1.48 \\
\hline Gearboxes & 6.83 & 6.83 & 6.83 & 7.17 & 8.96 & 1.44 & 1.34 & 0.80 \\
\hline Control Boxes & 2.16 & 0.54 & 0.54 & 0.54 & 0.54 & 0.41 & 0.54 & 0.41 \\
\hline Wiring & 4.80 & 4.80 & 4.80 & 5.04 & 6.30 & 1.42 & 0.94 & 0.79 \\
\hline Angle Sensors & 0.44 & 0.44 & 0.44 & 0.44 & 0.44 & 0.31 & 0.44 & 0.31 \\
\hline Tension Sensors & 0.26 & 0.26 & 0.26 & 0.26 & 0.26 & 0.20 & 0.26 & 0.20 \\
\hline Cameras & 0.33 & 0.66 & 0.66 & 0.66 & 0.66 & 0.66 & 0.66 & 0.66 \\
\hline $\begin{array}{l}\text { Quick Change, Pads, } \\
\text { or Grippers }\end{array}$ & 2.27 & 2.27 & 2.27 & 2.27 & 2.27 & 2.27 & 1.13 & 1.13 \\
\hline Subtotal & & & & & & & & \\
\hline Growth: 30\% & 68.83 & 61.67 & 48.73 & 50.59 & 60.03 & 27.22 & 14.82 & 11.25 \\
\hline & 20.65 & 18.50 & 14.62 & 15.18 & 18.01 & 8.17 & 4.45 & 3.37 \\
\hline Total & & & & & & & & \\
\hline
\end{tabular}




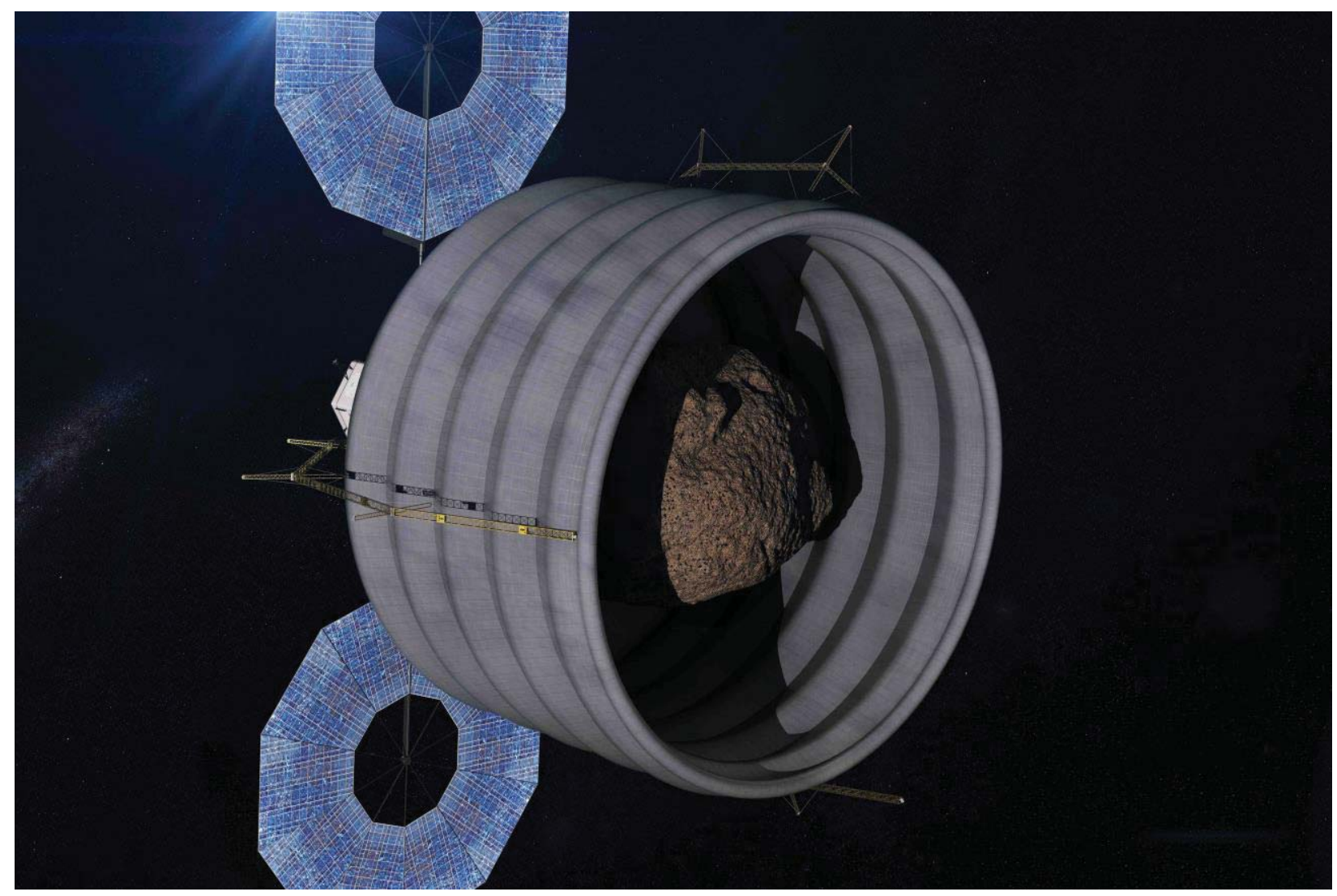

Figure 1. TALISMAN-based Concept A capture system. 


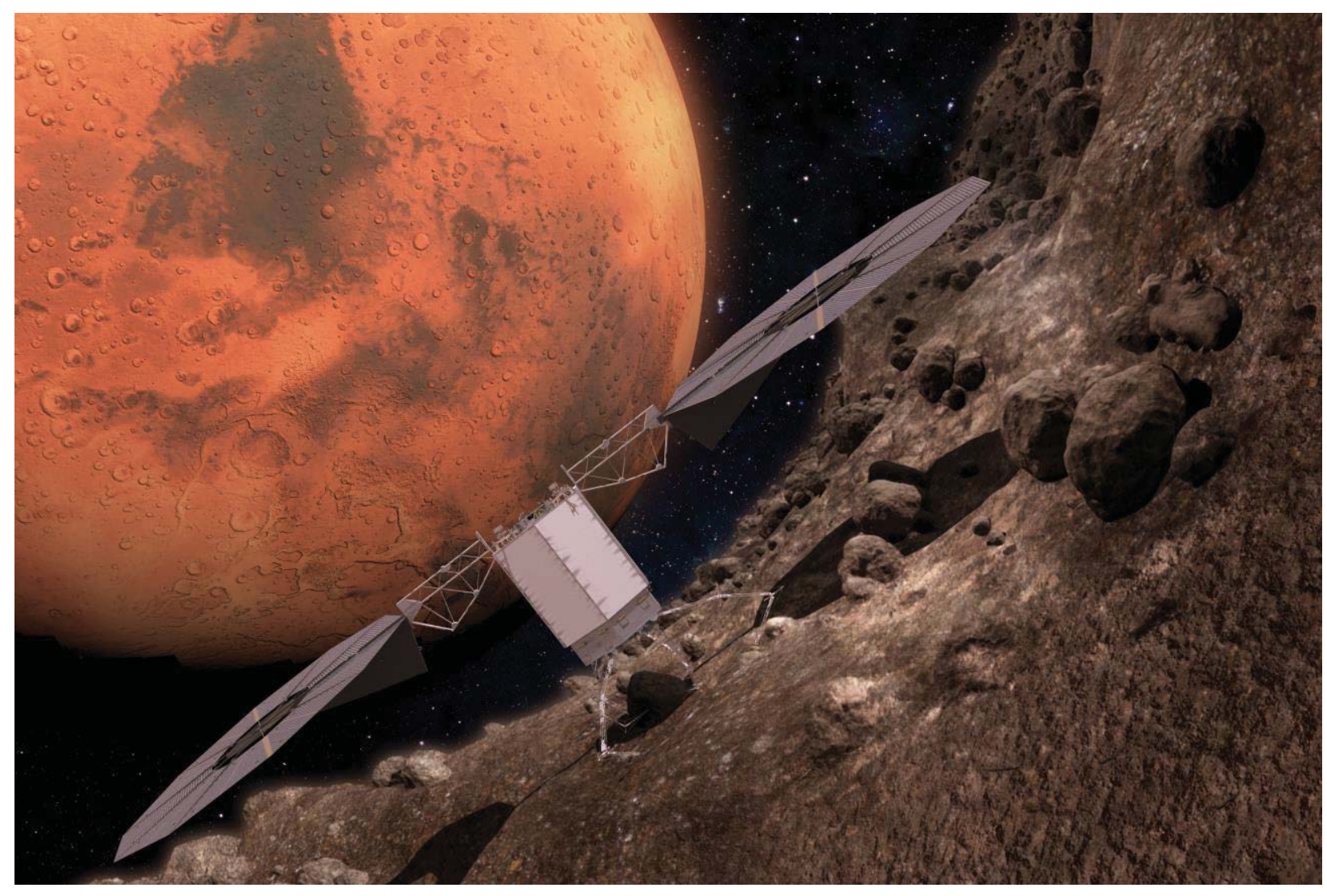

Figure 2. TALISMAN-based Concept B capture system. 


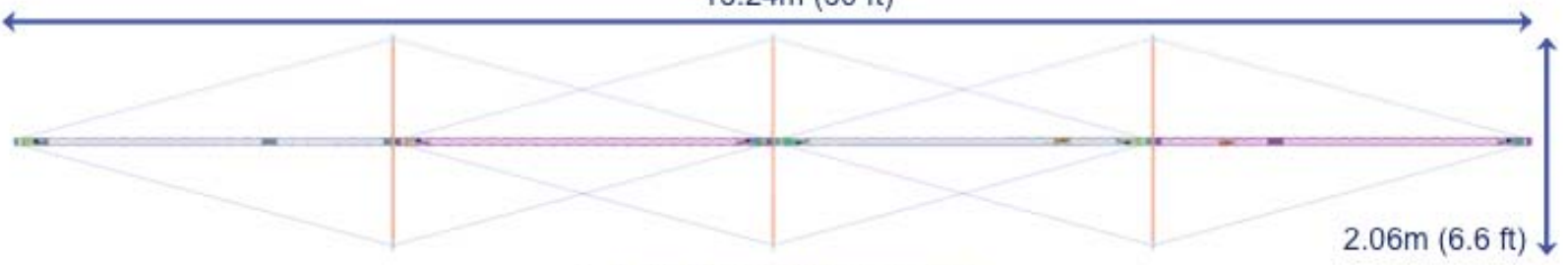

a. 4-link TALISMAN deployed.

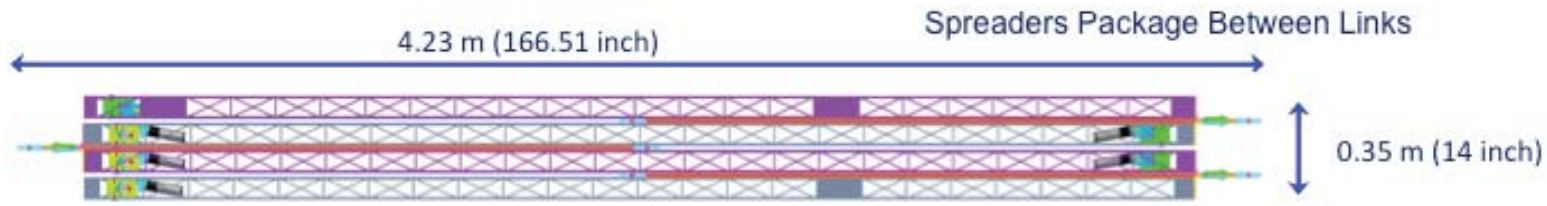

b. 4-link TALISMAN stowed for launch (top view).

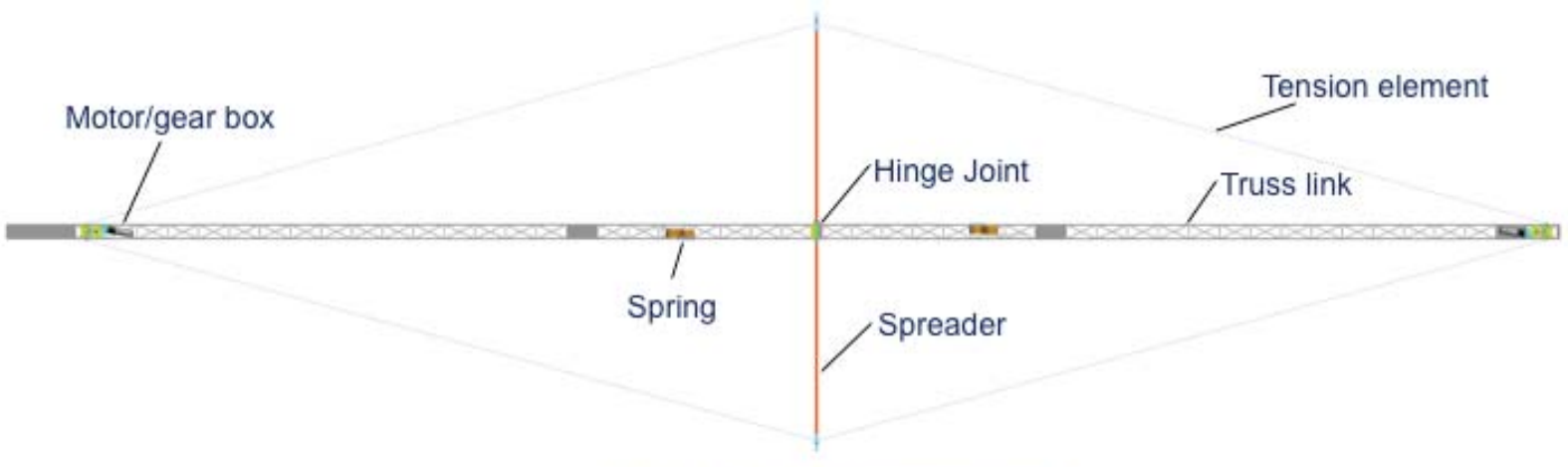

c. Major TALISMAN components.

Figure 3. Overview of TALISMAN features, members and components.

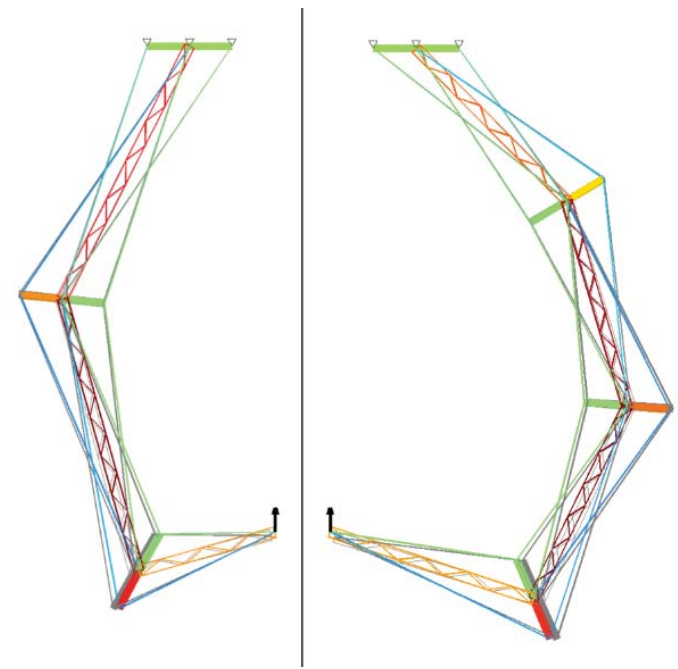

Figure 4. Example of two sizing runs with stresses shown. 

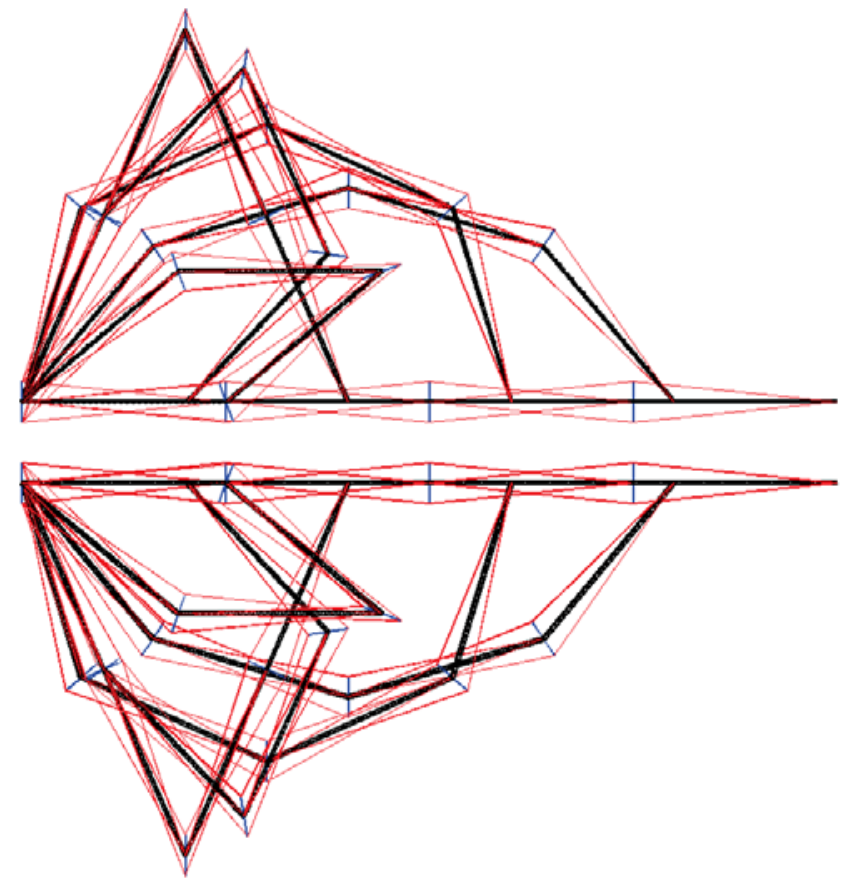

Figure 5. Example of multiple poses analyzed by MATLAB script.

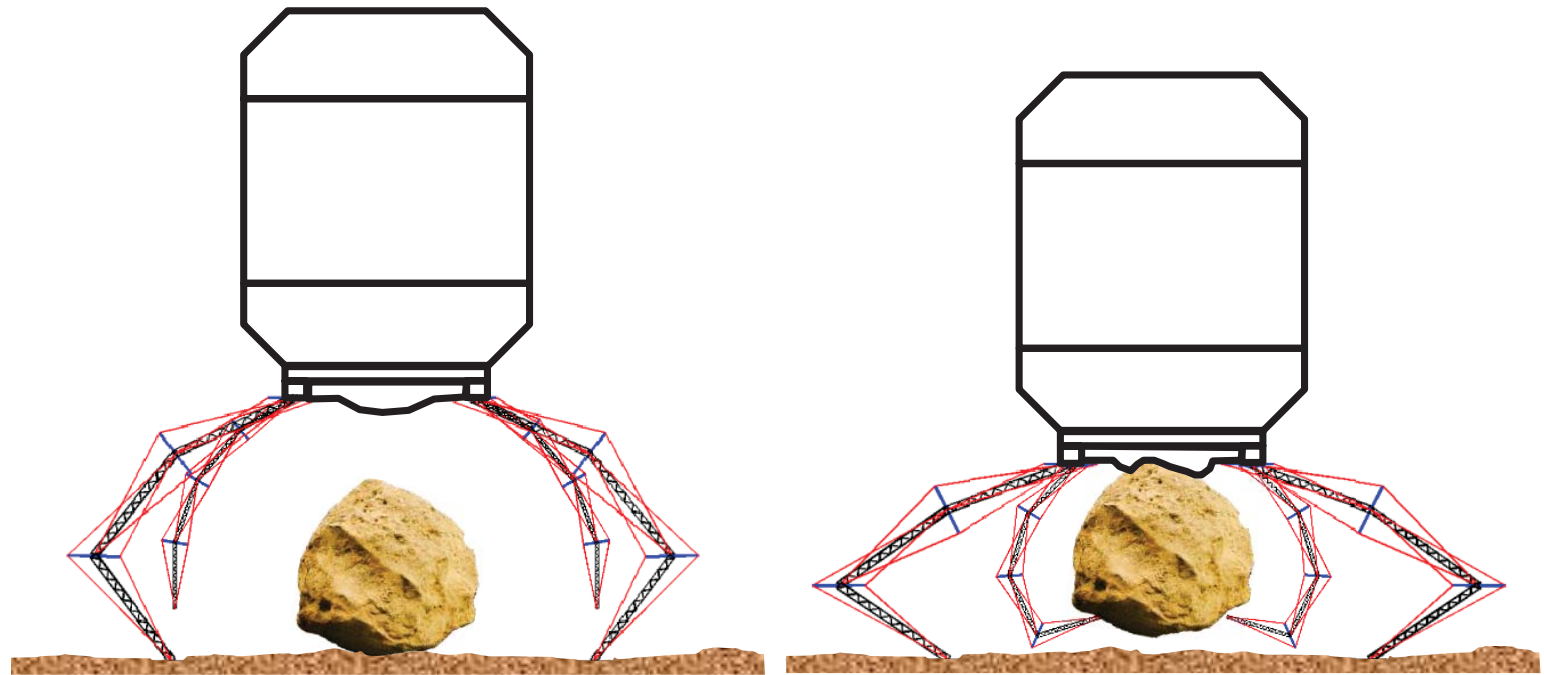

Figure 6. Example of plotting multiple poses from multiple systems analyzed by MATLAB script. 


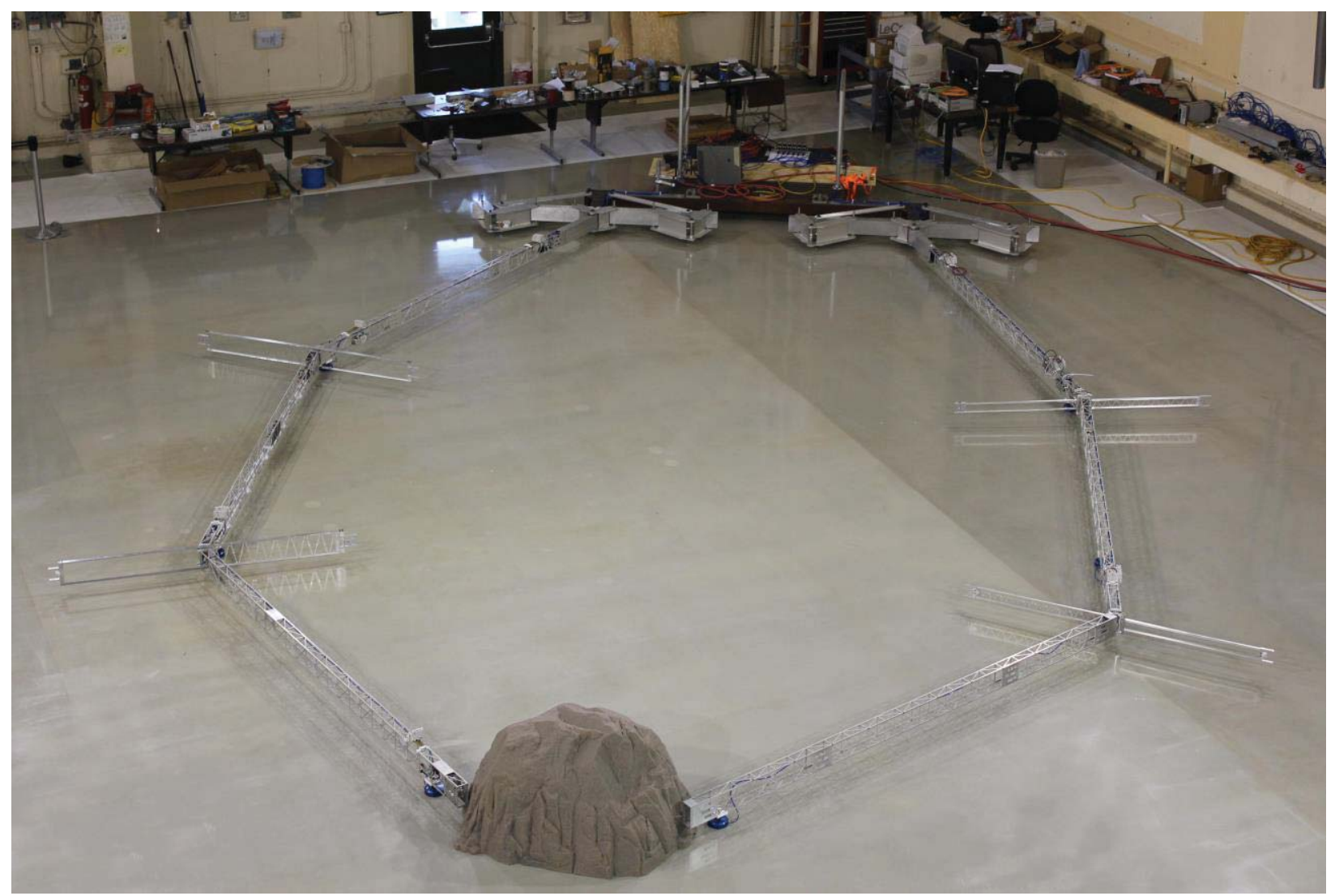

Figure 7. TALISMAN prototype hardware in laboratory. 


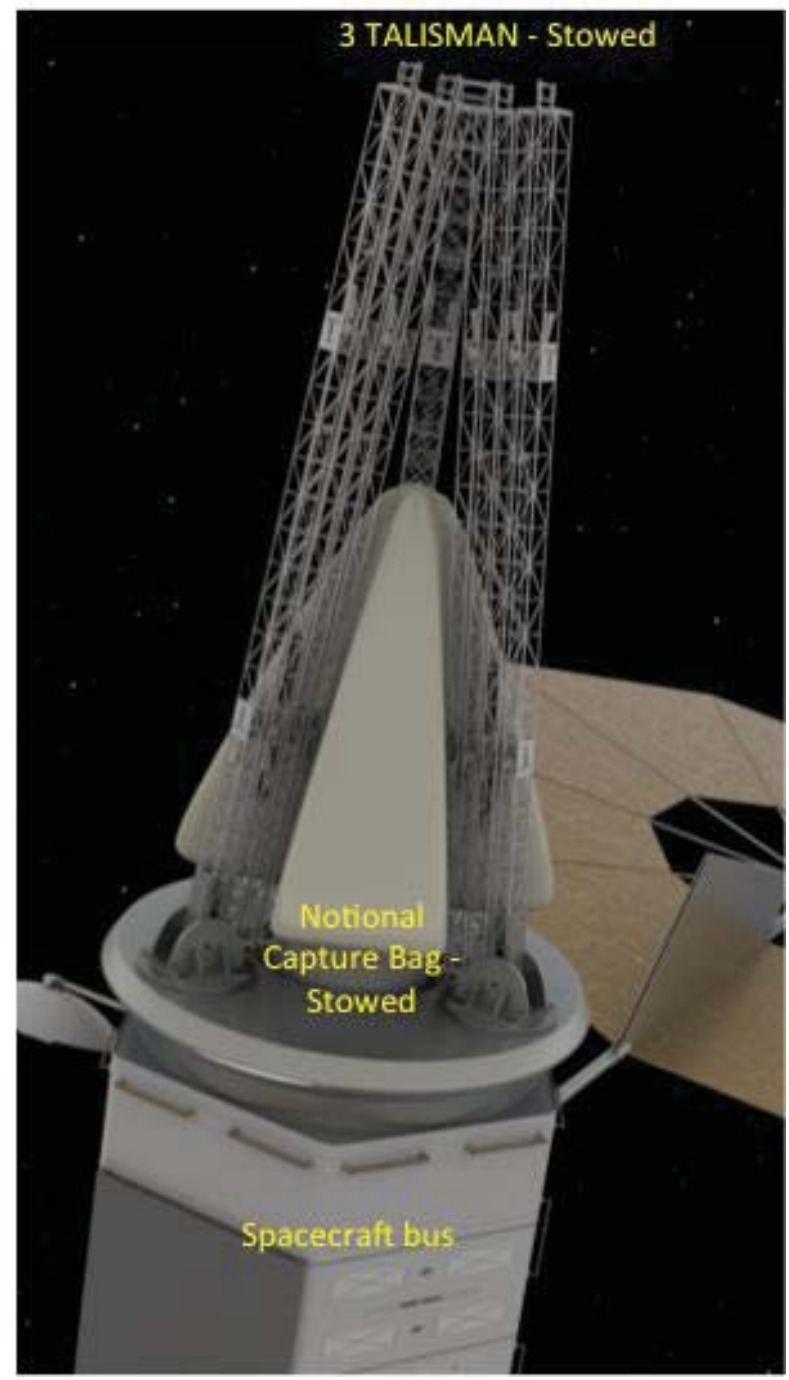

Figure 8. Capture System Concept A packaged for launch. 


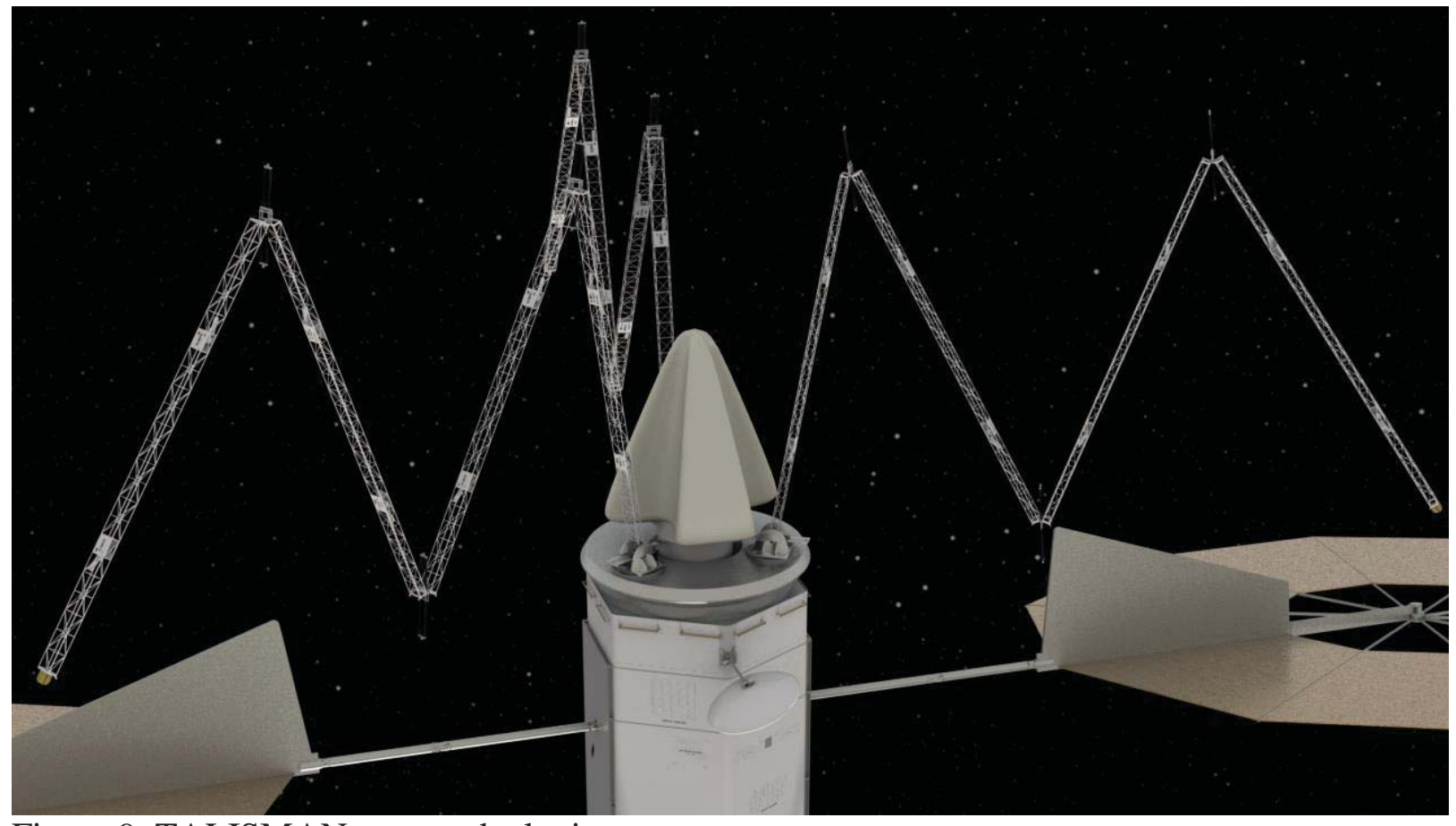

Figure 9. TALISMAN system deploying.

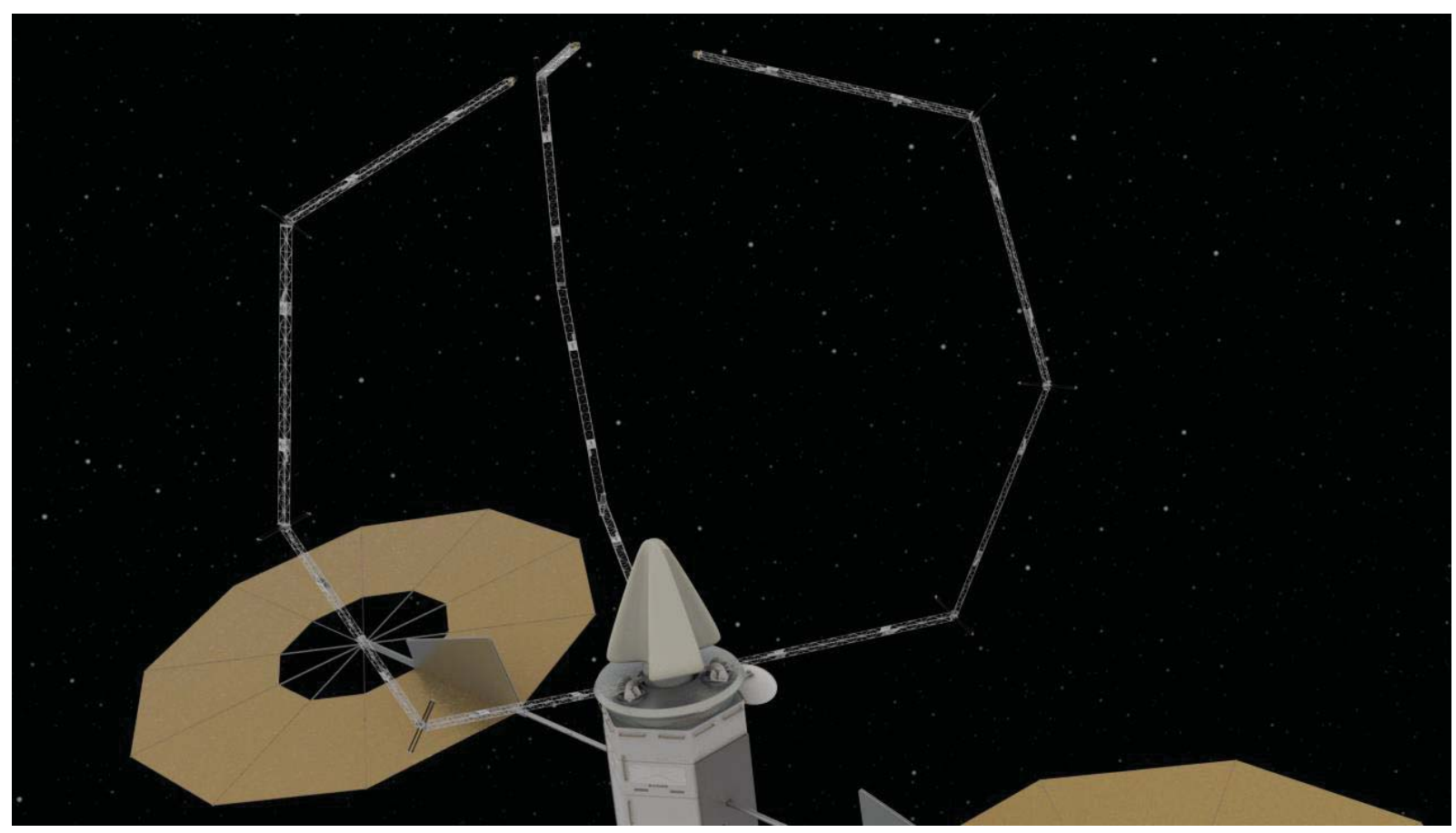

Figure 10. TALISMAN fully deployed. 


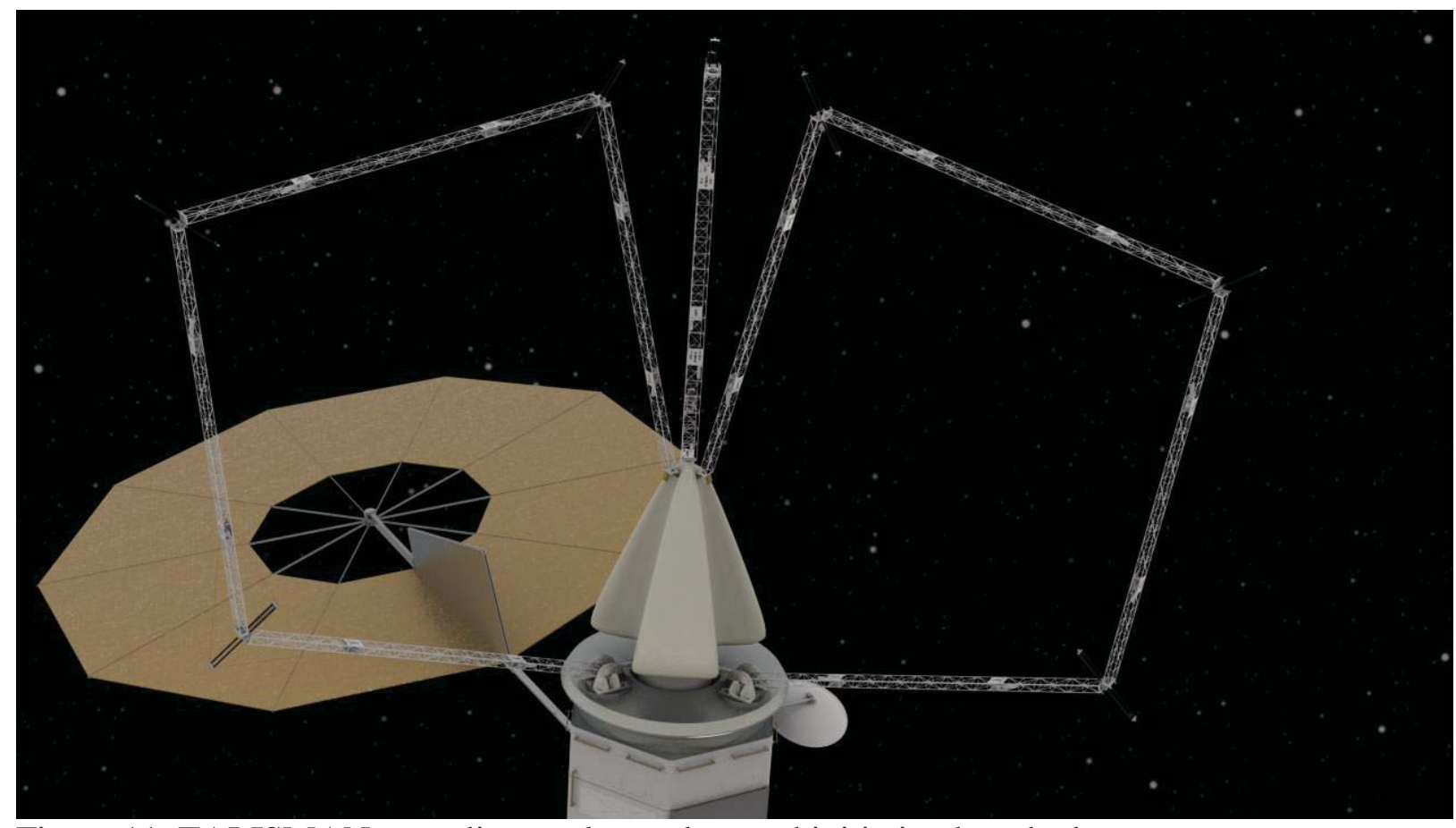

Figure 11. TALISMAN grappling enclosure bag and initiating bag deployment.

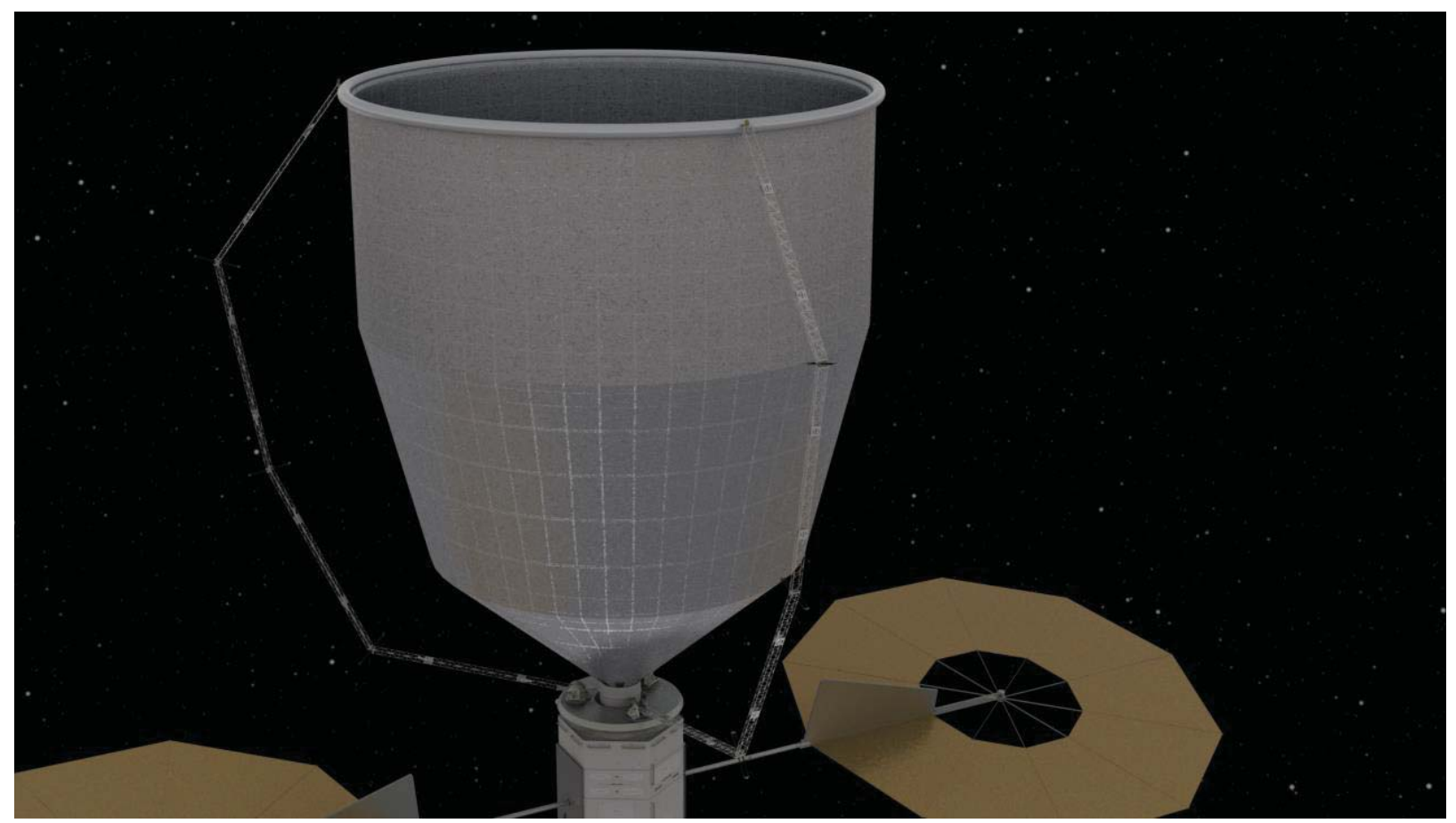

Figure 12. Capture system fully deployed. 


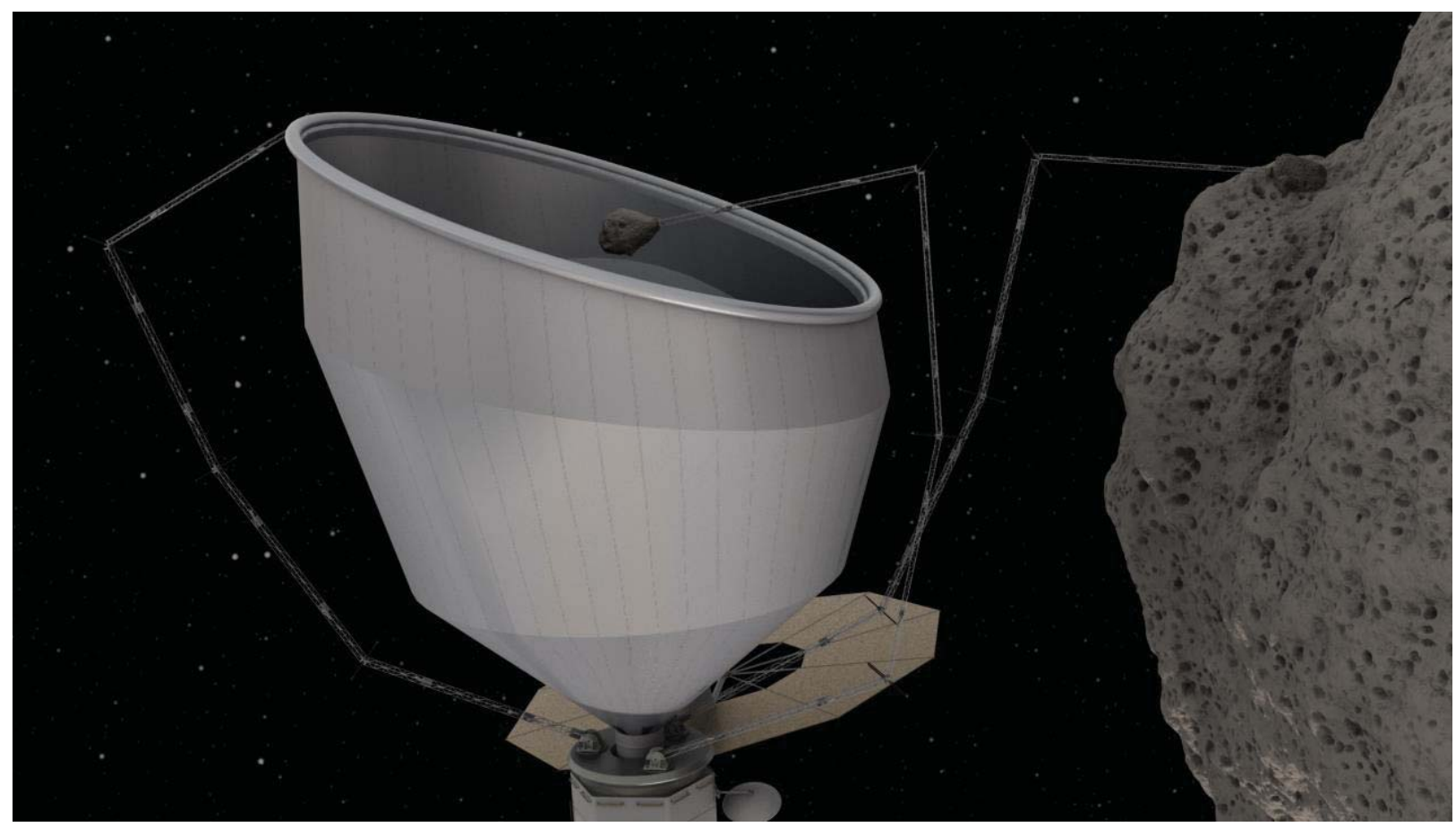

Figure 13. Applying TALISMAN Concept A capture system to mission concept B. 


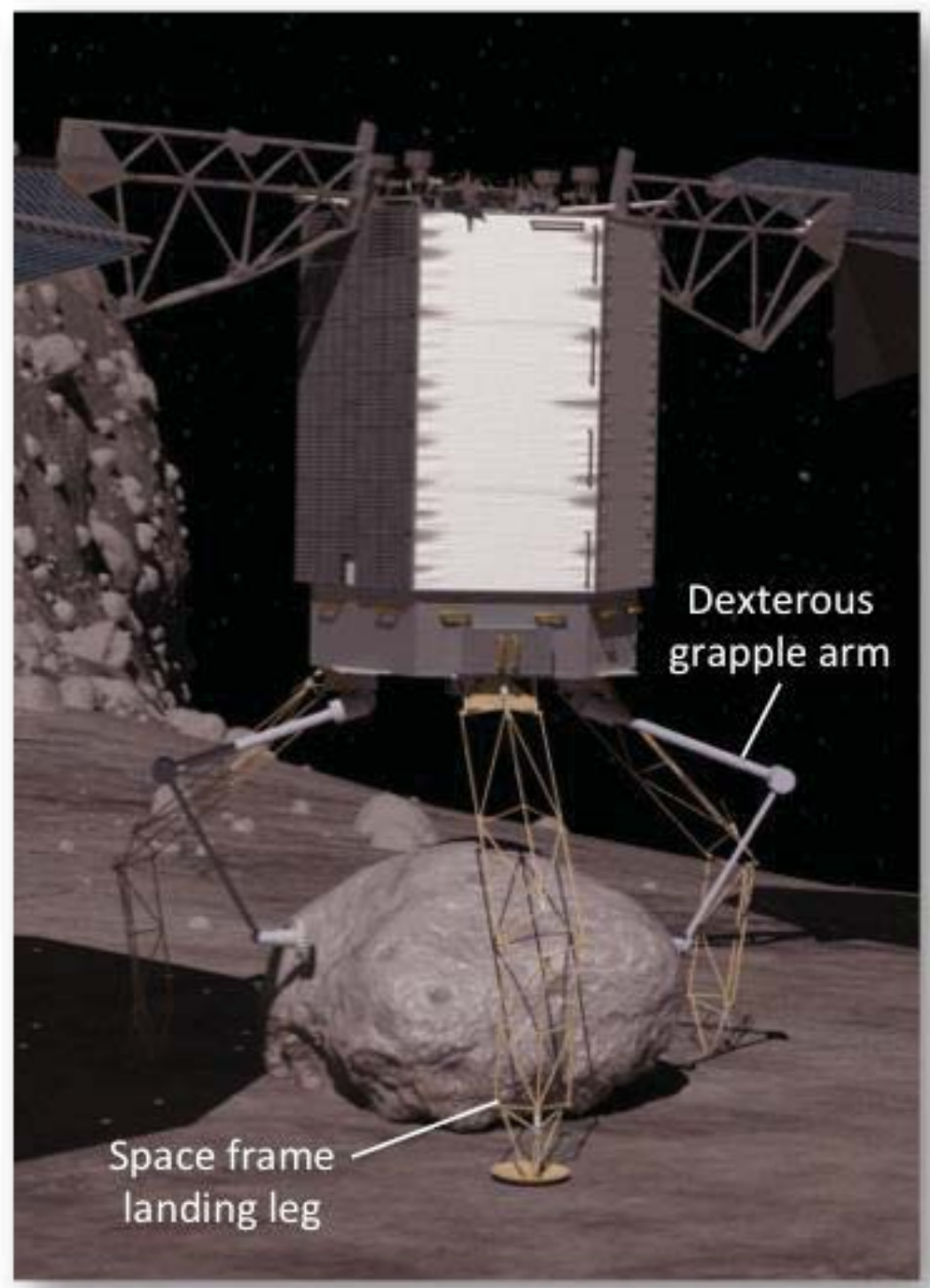

Figure 14. ARM Concept B reference capture system. 


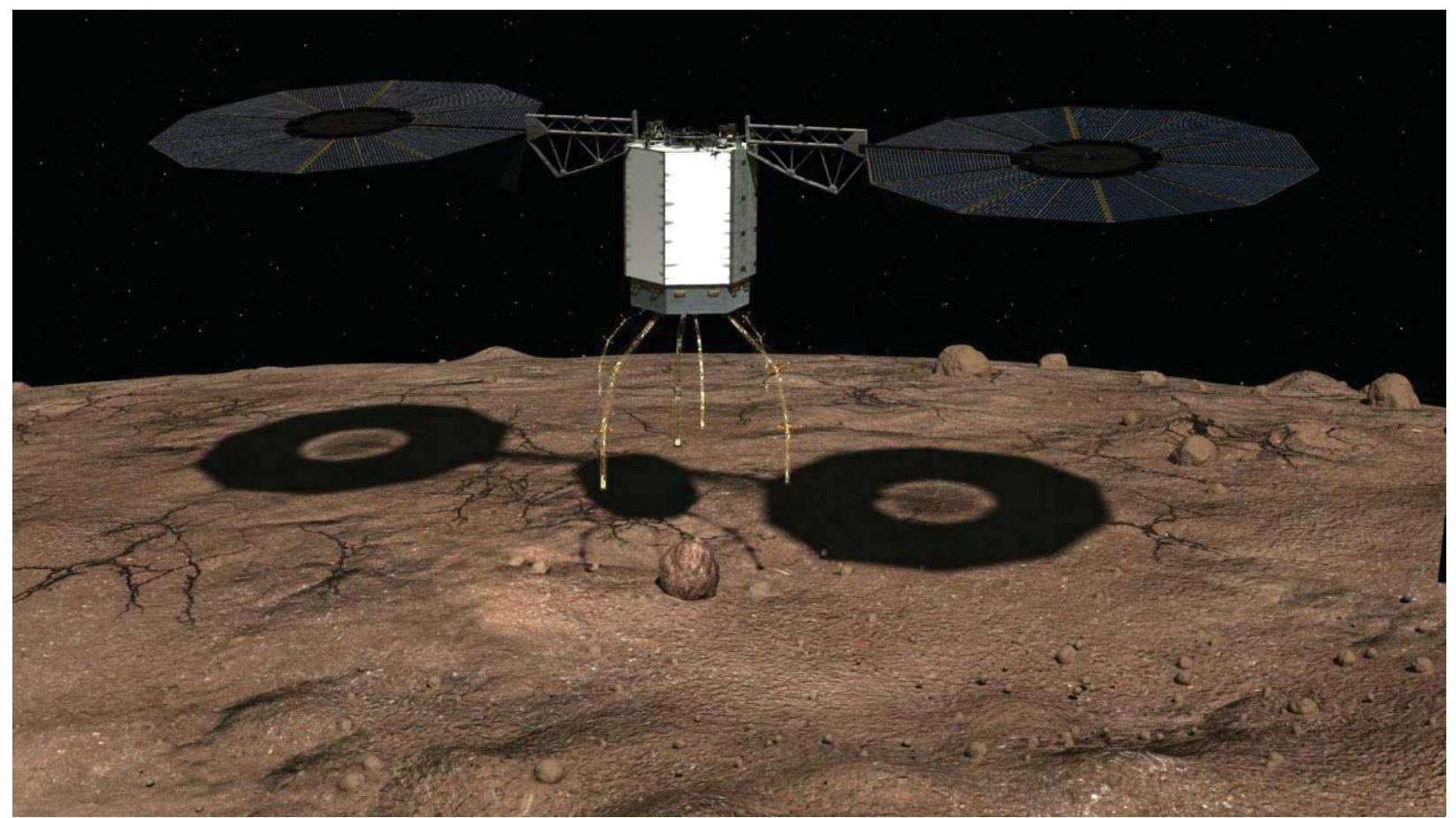

Figure 15. Mission Concept B approach and landing configuration.

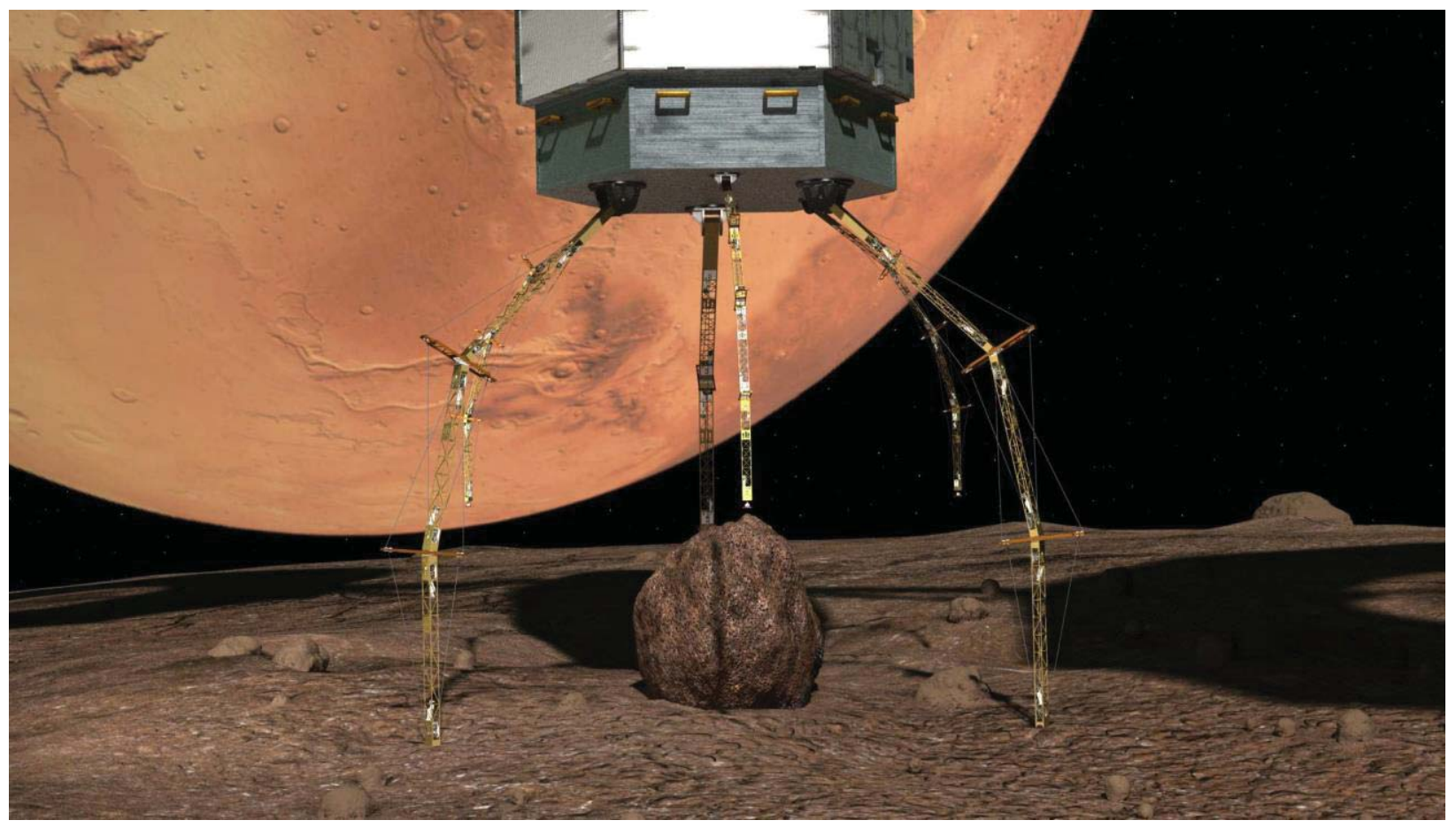

Figure 16. TALISMAN landing legs touch down on surface. 


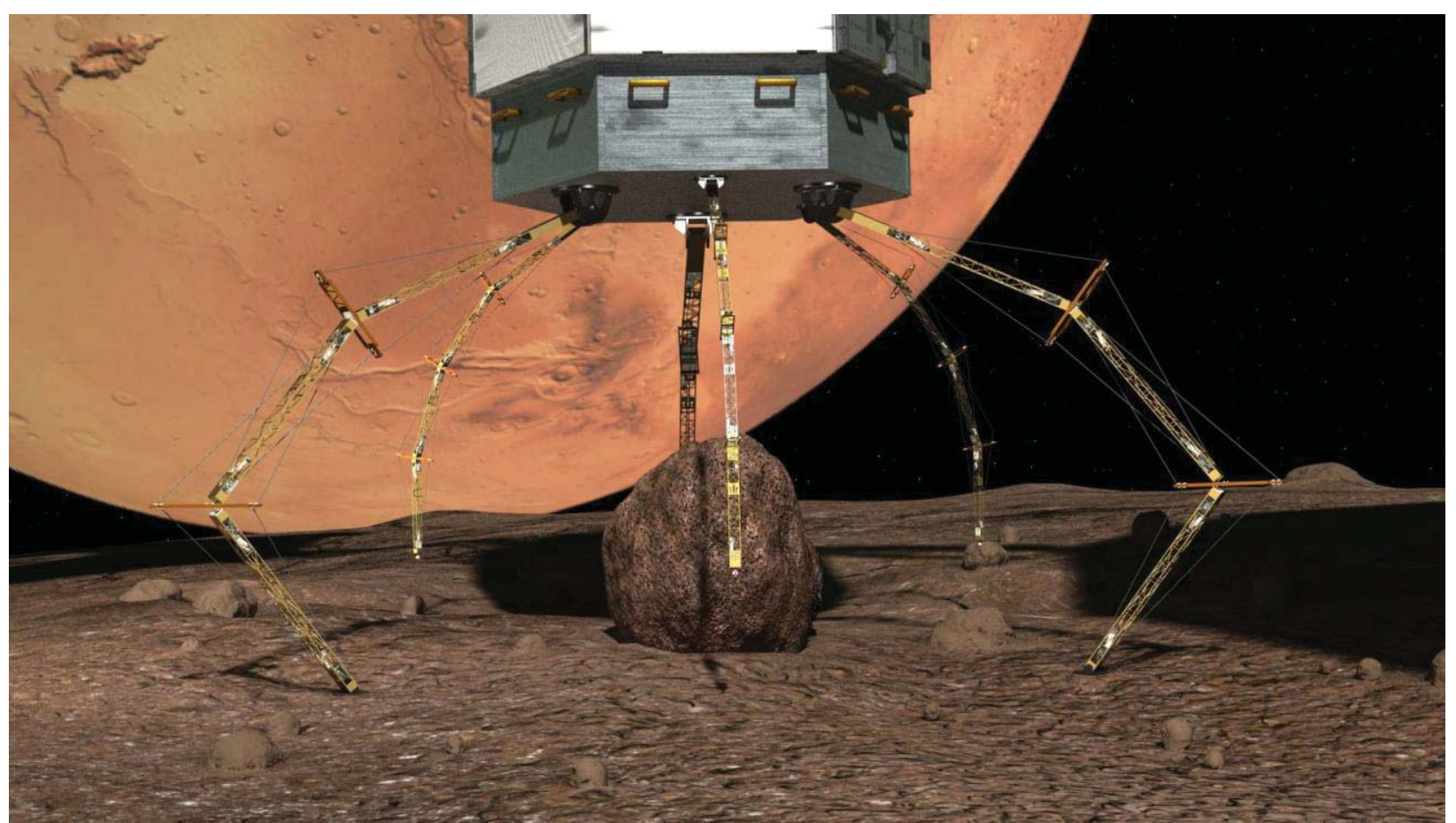

Figure 17. TALISMAN legs articulate and decelerate spacecraft.

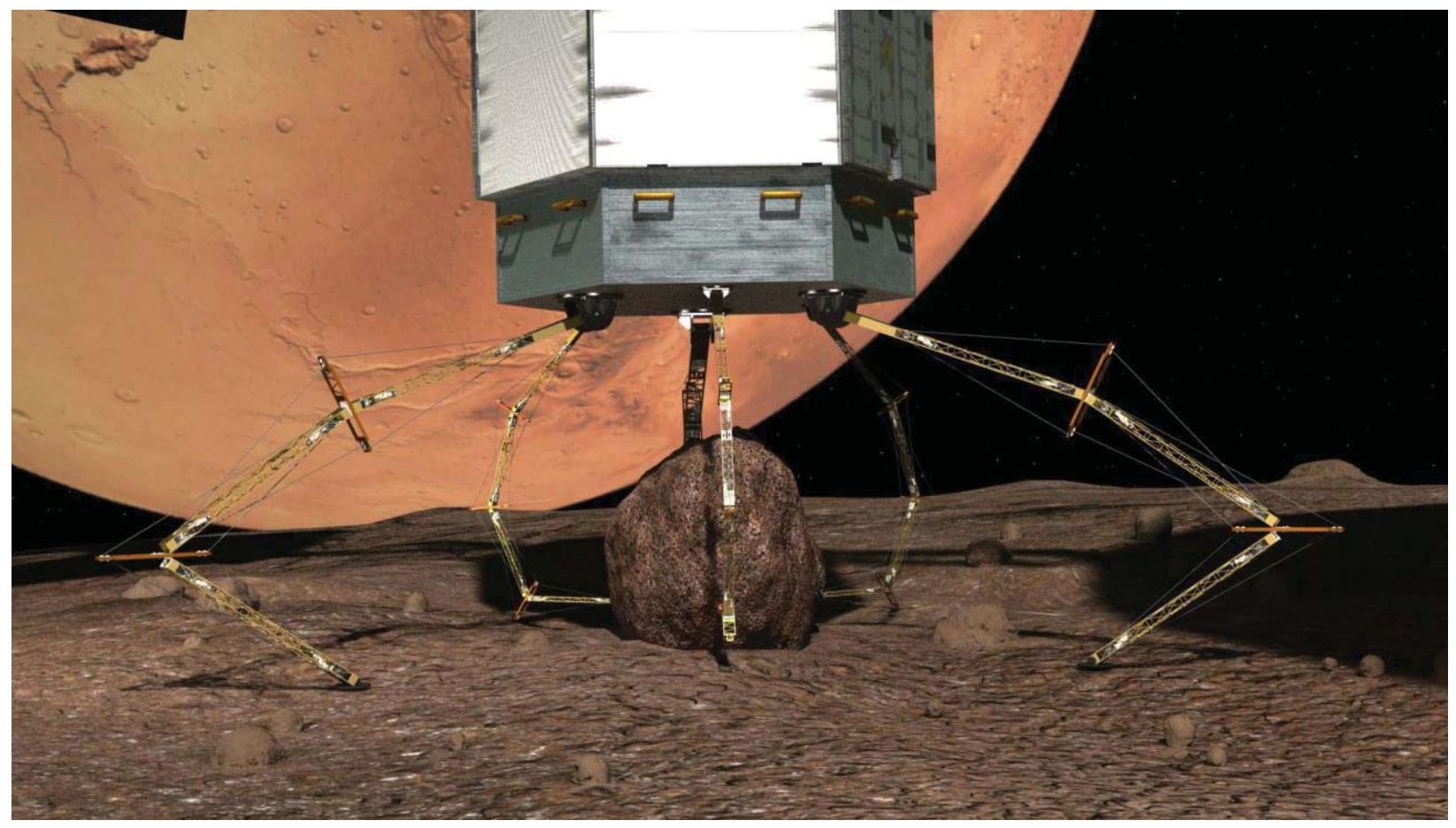

Figure 18. TALISMAN legs articulate further and enable grapple arms to grasp boulder. 


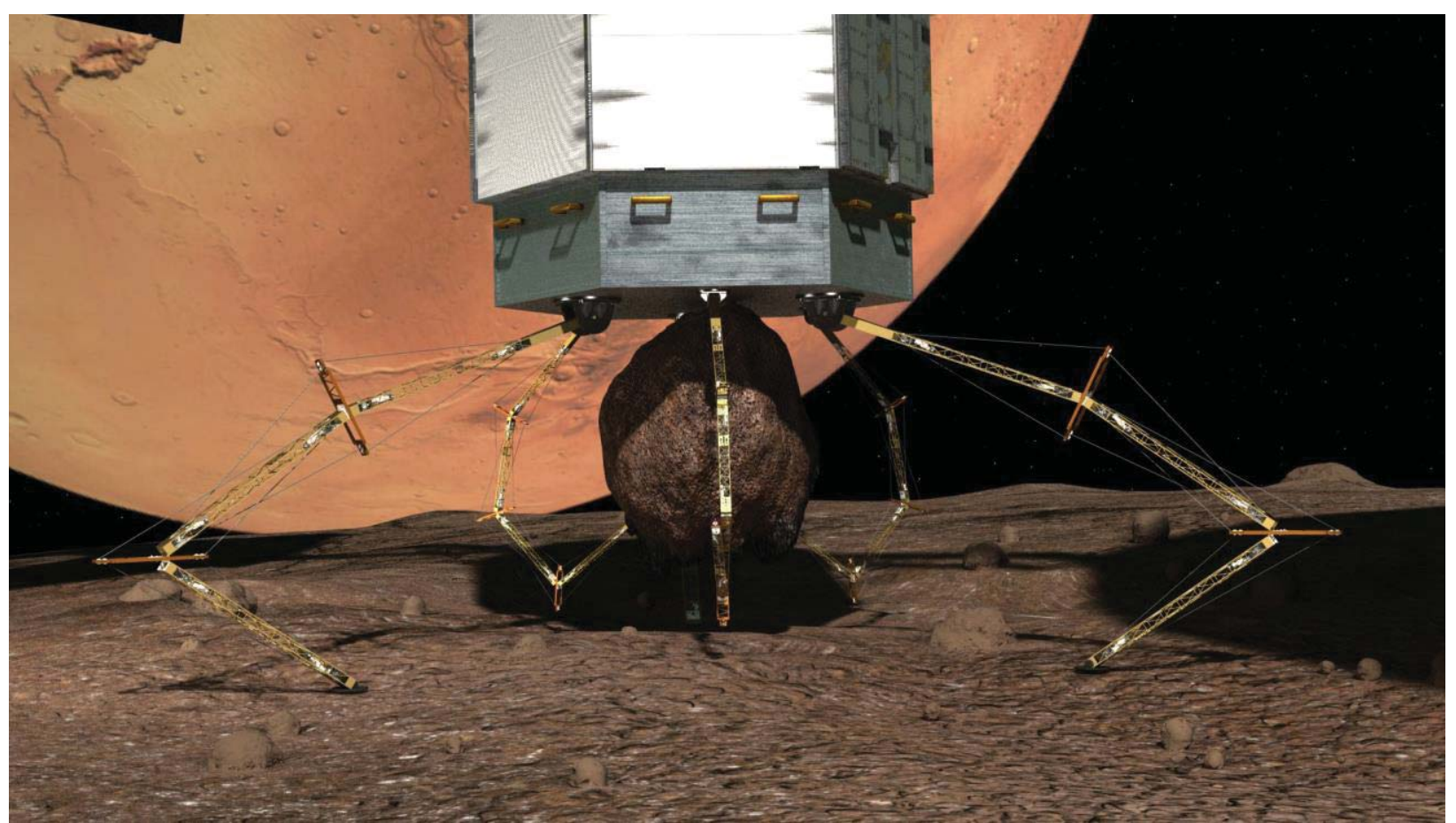

Figure 19. Grapple TALISMAN pluck boulder from surface and secure against spacecraft.

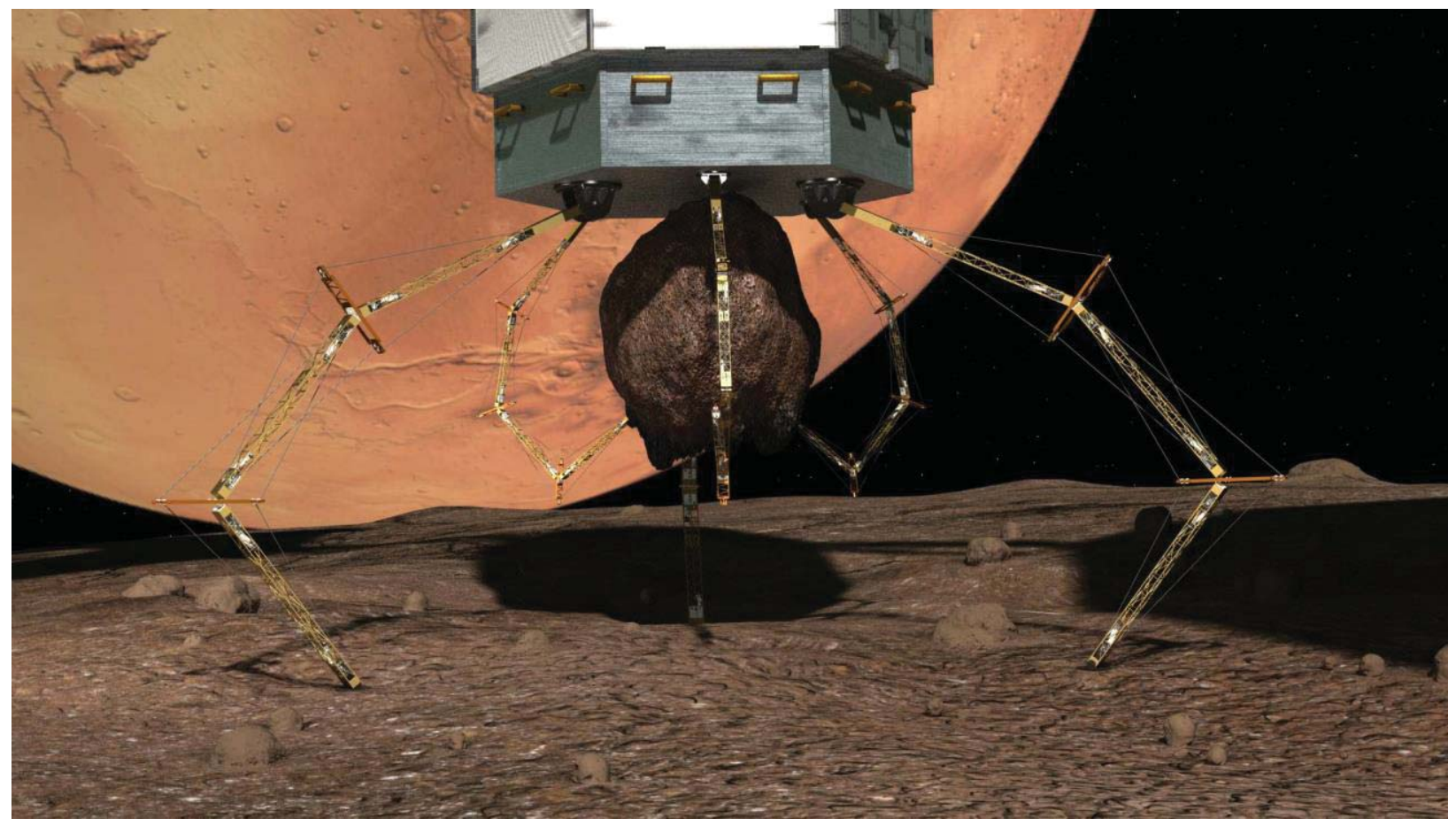

Figure 20. TALISMAN landing legs initiate push-off maneuver. 


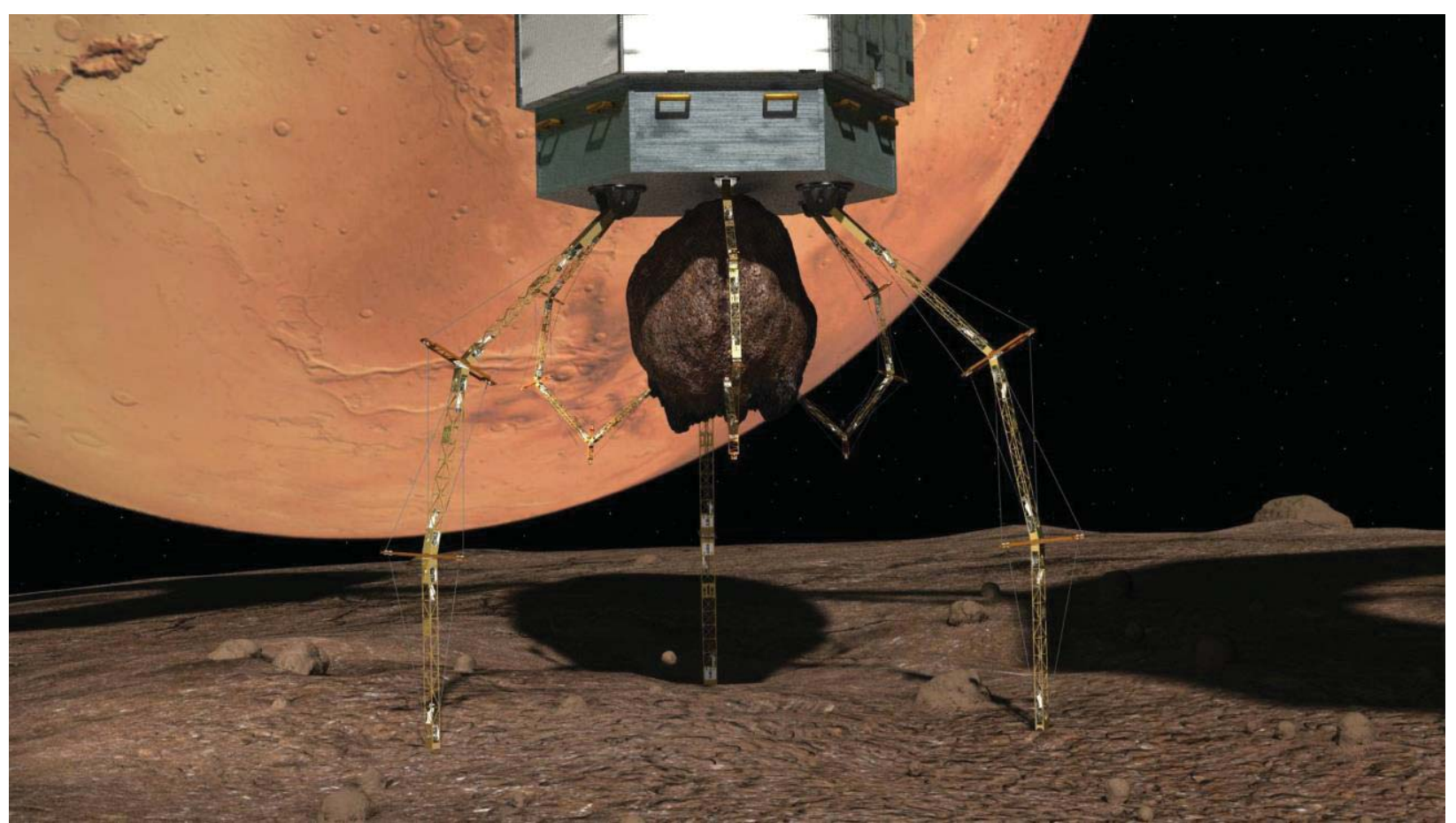

Figure 21. TALISMAN landing legs at full extension during push-off maneuver.

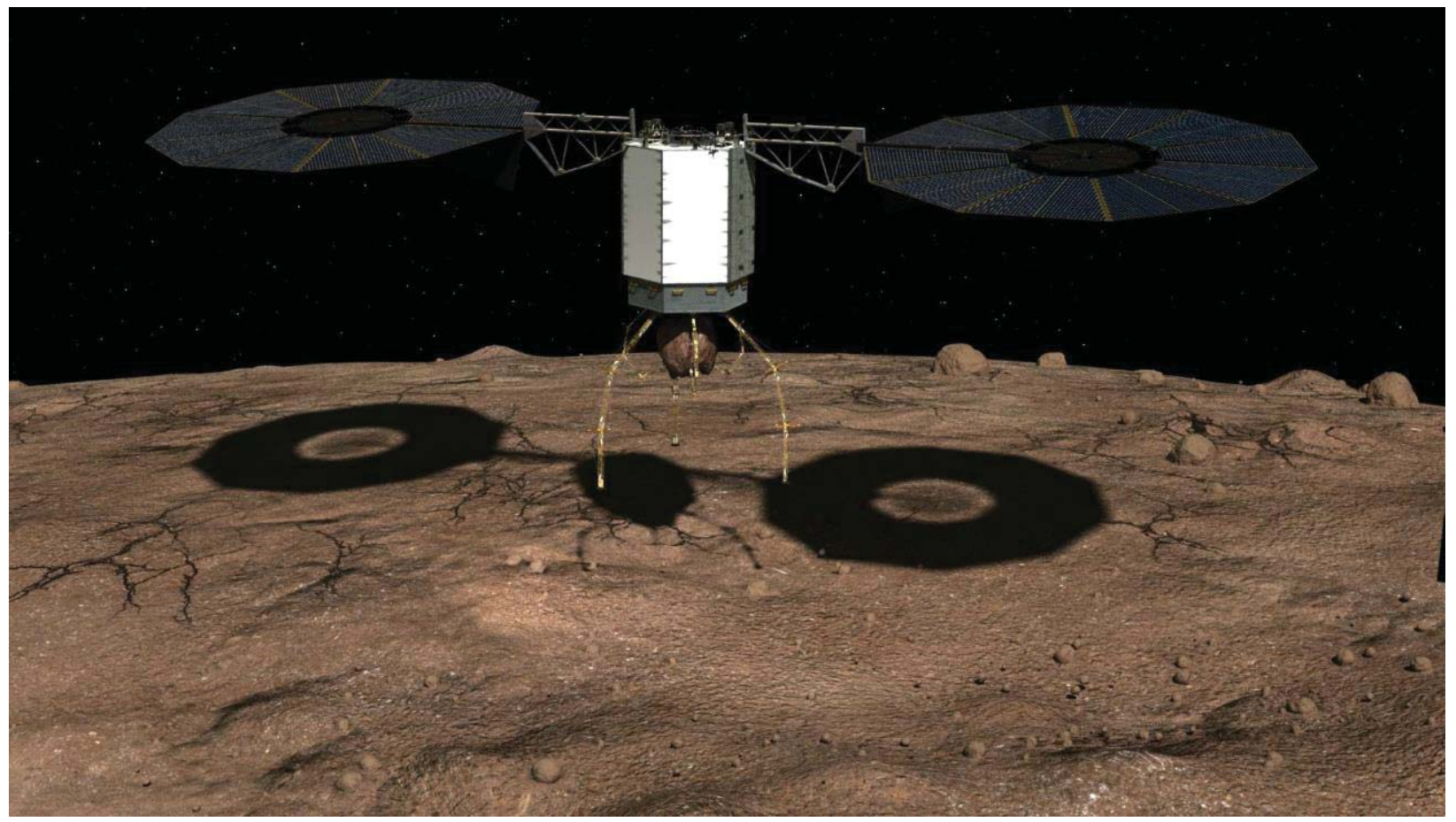

Figure 22. Spacecraft with secured boulder clears asteroid surface. 